\title{
Importance of Detailed Modeling of Loads/PV Systems Connected to Secondary of Distribution Transformers
}

\author{
Piyush Gupta
}

Thesis submitted to the faculty of the Virginia Polytechnic Institute and State University in partial fulfillment of the requirements for the degree of

Master of Science

In

Electrical Engineering

\author{
Robert P. Broadwater, Chair \\ Virgilio A. Centeno \\ Jaime De La Ree Lopez
}

$27^{\text {th }}$ September, 2017

Blacksburg, Virginia

Keywords: Simple Secondary Model, Detailed Secondary Model, Cloud Motion Simulator, Distributed Energy Resources 
Importance of Detailed Modeling of Loads/PV Systems Connected to Secondary of

Distribution Transformers

\author{
Piyush Gupta
}

\begin{abstract}
Residential solar Photovoltaic (PV) installations are increasing at a very high pace in the United States. In 2017 there are approximately one million residential solar PV installations in the US. A significant share of these installations are downstream of distribution transformers and thus connected to the secondary. To precisely analyze voltage variations induced by PV systems into distribution systems, accurate models of load and PV systems connected to the secondary side of distribution transformers are required. In the work here we consider two secondary circuit modeling approaches, simple secondary and detailed secondary models. In simple secondary models all loads and all PV generators below a distribution transformer are modeled as an aggregate load and an aggregate PV generator. In the detailed secondary models all loads and PV systems below the distribution transformers are modeled individually and secondary conductors and service drops are also modeled. Using a cloud motion simulator, it is observed that employing the simple secondary models can lead to inaccurate and conservative results. Moreover, the locations with the greatest voltage changes are different in the two modeling approaches. This paper highlights the importance of utilizing detailed secondary models over simple secondary models in analyzing PV generation.
\end{abstract}


Importance of Detailed Modeling of Loads/PV Systems Connected to Secondary of

Distribution Transformers

\author{
Piyush Gupta
}

\title{
GENERAL AUDIENCE ABSTRACT
}

Power system planners and operators rely on computer-based modeling and analysis of the electric grid to ensure that electricity is delivered to consumers in a reliable manner. The current modeling is done either to simulate the high voltage transmission networks, or the primary distribution networks. Till now these modeling approaches have worked well as the electricity flow in the electric grid is largely unidirectional, i.e. power flows from the transmission network to the distribution network. Neglecting the secondary distribution network topology in such a structure of the electric grid does not introduce significant calculation errors. However, the rapid growth of residential solar PV based distributed generation over the last few years, which is expected to continue into the foreseeable future, has motivated the need to rethink this modeling and analysis paradigm. As the penetration levels of distributed generation increase, there will be bi-directional flow of electricity between the transmission and distribution networks. Accurate analysis of such a decentralized electric grid cannot be performed if secondary distribution network topology is neglected in the models. So, to precisely analyze voltage variations induced by PV systems into distribution systems, accurate models of load and PV systems connected to the secondary side of distribution transformers are required. This thesis highlights the importance of using detailed models of secondary distribution. 


\section{Acknowledgement}

I wish to extend my sincerest gratitude to Dr. Robert Broadwater for his guidance and support throughout this thesis work. I have had countless discussions and brain storming sessions with him which have filled me with inspiration and broadened the scope of my thinking.

I am very thankful to Dr. Virgilio Centeno for his invaluable insights. His generous assistance has gone from technical and academic discussions, financial support for the research work and always being there to guide me in the right direction.

I am very grateful to Dr. Jaime De La Ree who has constantly supported me. I have learnt a lot from him, especially through a capstone project. I thank him for his contributions in my integral growth as a person. He always provides me with a helping hand whenever I need it. I would also like to thank him for providing me with the financial support to pursue my education in my own way.

I would like to thank Kaveh Rahimi, Manish Kumar Singh and Tapas Barik, who have been my first guiding sources for all my queries and they have always responded by helping me out. The healthy academic environment provided by the students at the Power Lab always spark my interest to learn more. I would like to extend my gratitude to my lab mates - Kunal, Sarthak, Shubham, Aditya, Chetan, Siddharth, Pearl, Elliott, Andreas, Chen, Huiying and Xiawen. A special thanks to my friends Mayank, Sandeep and Trisha, Adbhut, Manjot, Gaurav, Jashan, Raja, Mohit, Bharti, Sandeep Hans and Srivats for their support and memorable time in Blacksburg. I would also like to thank my friends Rishi, Parne, Shilpi, Akash, Hemant, Pritpal, Varinder and Mayank who stood by me during difficult times and always motivated me during my journey from Banaras to Blacksburg.

I would like to thank Karen Wills for helping me with all the documentation in graduate school.

Finally, I would like to thank my parents - Sushma and Naresh Gupta, aunt and uncle - Lata and Vinod Gupta, sister in law and brother - Swati and Vikrant Gupta, sister - Chinali Gupta, and brother - Vinit Gupta for their perennial love and motivation. 


\section{Table of Contents}

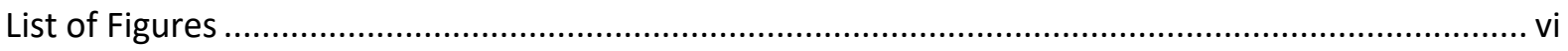

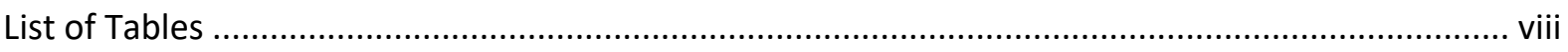

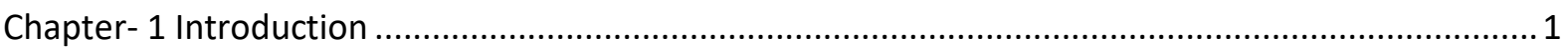

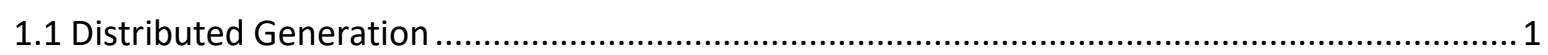

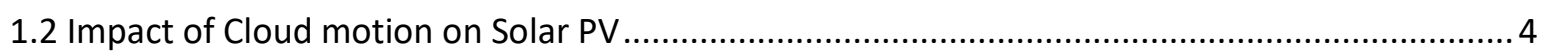

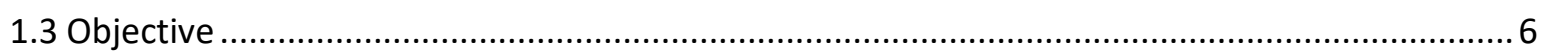

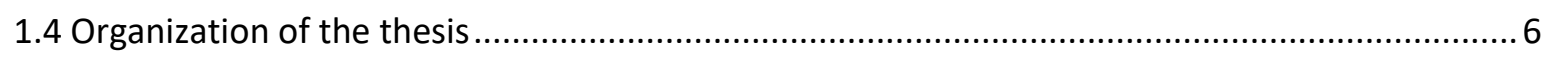

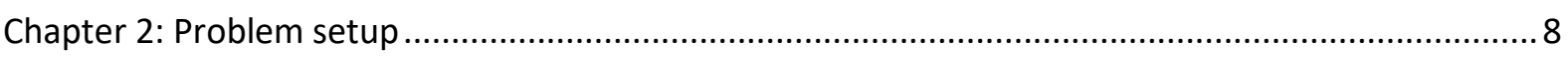

2.1 Introduction on the two analysis approaches being compared (Traditional simple model;

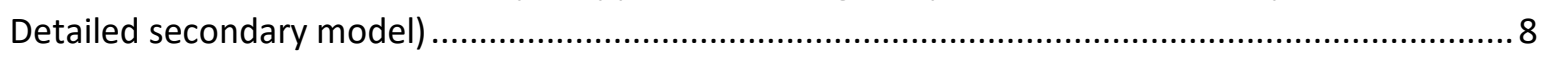

2.2 Details of distribution network employed for study....................................................... 10

2.3 Cloud Motion Simulator .................................................................................... 11

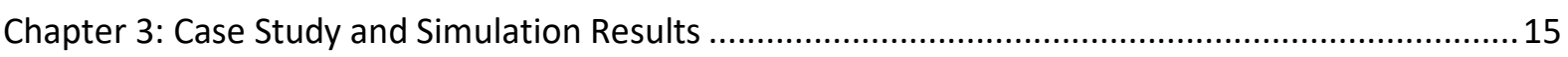

3.1 Comparison of cloud motion impact analysis with simple secondary and detailed secondary modeling

3.2 Analysis for dependence of voltage variation estimation error with different loading (Maximum/Minimum Load) and number of connected customers ........................................... 18

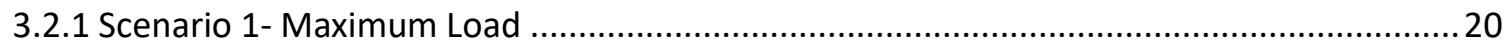

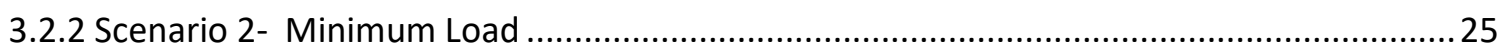

3.3 Inferences from the results obtained; Discussions on reasons justifying the difference in results obtained from the two analysis/modelling approaches........................................................ 31

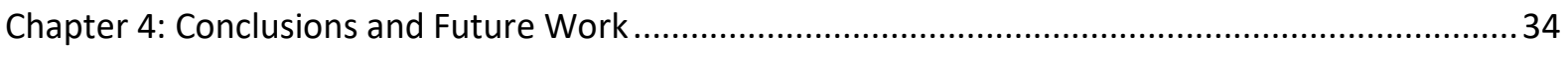

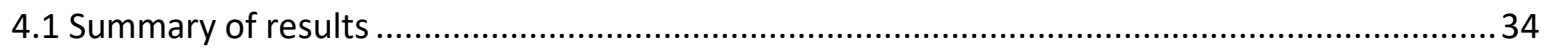

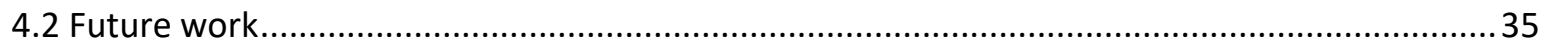

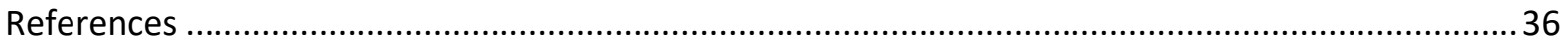




\section{List of Figures}

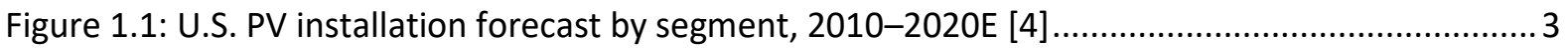

Figure 1.2: Zones showing areas of low and high solar variability [20] .......................................... 5

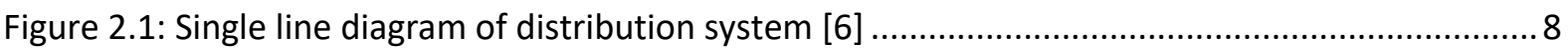

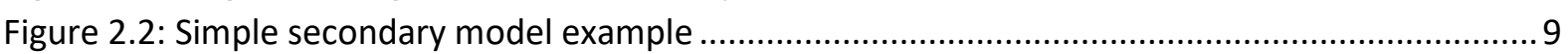

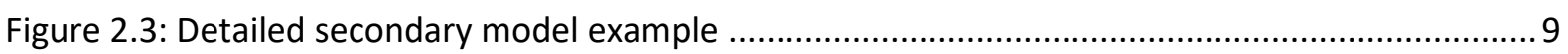

Figure 2.4: Distribution feeder with detailed secondary models, with a zoom-in or blowup of one

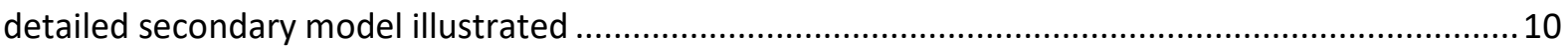

Figure 2.5: Distribution feeder with simple secondary models, where the same model is used for

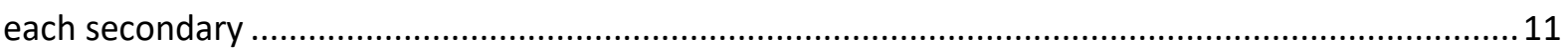

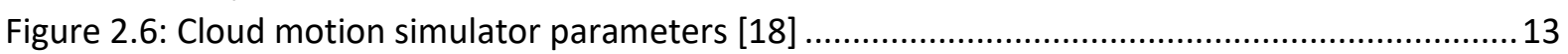

Figure 2.7: Cloud motion simulator interaction with power flow analysis [18] ............................... 14

Figure 3.1: Locations with highest decrease in voltage over one second for simple and detailed

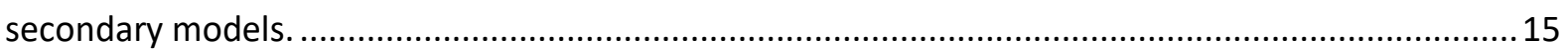

Figure 3.2: Absolute value of voltage decrease rate for simple and detailed secondary models........ 17

Figure 3.3: Flicker values for simple secondary models and detailed secondary models ................... 18

Figure 3.4: Load profile for simple secondary and detailed secondary models ................................ 19

Figure 3.5: Absolute value of the errors associated with maximum voltage decrease rate between

the simple and detailed models versus number of secondary customers ........................................... 21

Figure 3.6: Percentage errors in prediction of maximum voltage decrease rates, along with

associated PV penetration levels, versus number of secondary customers ....................................... 21

Figure 3.7: Absolute value of the errors associated with mean voltage decrease rate between the

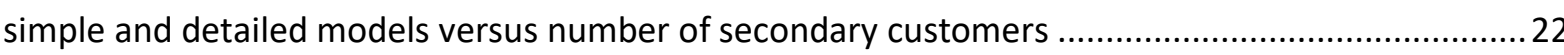

Figure 3.8: Percentage errors in prediction of mean voltage decrease rates, along with associated PV

penetration levels, versus number of secondary customers..........................................................23

Figure 3.9: Absolute value of the errors associated with minimum voltage decrease rate between the simple and detailed models versus number of secondary customers ...............................................2 24

Figure 3.10: Percentage errors in prediction of minimum voltage decrease rates, along with associated PV penetration levels, versus number of secondary customers ......................................24

Figure 3.11: Absolute value of the errors associated with maximum, mean, and minimum voltage decrease rates between the simple and detailed models versus number of secondary customers ... 25 Figure 3.12: Percentage errors in prediction of maximum, mean, and minimum voltage decrease rates, along with associated PV penetration levels, versus number of secondary customers .............2 25 Figure 3.13: Absolute value of the errors associated with maximum voltage decrease rate between the simple and detailed models versus number of secondary customers ..........................................26

Figure 3.14: Percentage errors in prediction of maximum voltage decrease rates, along with associated PV penetration levels, versus number of secondary customers

Figure 3.15: Absolute value of the errors associated with mean voltage decrease rate between the simple and detailed models versus number of secondary customers

Figure 3.16: Percentage errors in prediction of mean voltage decrease rates, along with associated PV penetration levels, versus number of secondary customers

Figure 3.17: Absolute value of the errors associated with minimum voltage decrease rate between the simple and detailed models versus number of secondary customers... 
Figure 3.18: Percentage errors in prediction of minimum voltage decrease rates, along with associated PV penetration levels, versus number of secondary customers ...

Figure 3.19: Absolute value of the errors associated with maximum, mean, and minimum voltage decrease rates between the simple and detailed models versus number of secondary customers ... 30 Figure 3.20: Percentage errors in prediction of maximum, mean, and minimum voltage decrease rates, along with associated PV penetration levels, versus number of secondary customers .31 


\section{List of Tables}

Table 2.1: Cloud motion simulator input parameters

Table 3.1: Rate of voltage decrease for simple and detailed secondary circuits for locations with highest changes

Table 3.2: Errors in rate of voltage decrease for simple models and detailed secondary models....... 17

Table 3.3: Flicker value comparisons for simple and detailed secondary circuits............................. 18

Table 3.4: Percentage voltage decrease errors for simple models and detailed secondary models ... 20

Table 3.5: Percentage voltage decrease errors for simple models and detailed secondary models ... 22

Table 3.6: Percentage voltage decrease errors for simple models and detailed secondary models ... 23

Table 3.7: Percentage voltage decrease errors for simple models and detailed secondary models ... 26

Table 3.8: Percentage voltage decrease errors for simple models and detailed secondary models ... 27

Table 3.9: Percentage voltage decrease errors for simple models and detailed secondary models ... 29 


\section{Chapter- 1 Introduction}

Traditionally the distribution system has been designed to operate with unidirectional power flow where power flows from a substation to loads. That scenario has started to change with the passage of Public Utility Regulatory Policies Act in 1978, after which Distributed Generation (DG) started appearing on the distribution system. With the improvement in economic viability, technical advancement, and the restructuring of wholesale and retail markets for electric power, there has been a drastic increase in the use of DG at the distribution level [1].

Traditionally, a simple secondary model of distribution transformers has been used to analyze the distribution system in which the individual loads and PV systems have been combined below a distribution transformer, representing them as a single load and a single PV system. However, there has been a drastic change in the past decade, with the integration of Distributed Generation (DG) at the distribution level, that makes analysis results from the traditional model not sufficient. Thus, the generation added at the distribution level has fundamentally changed the power flow conditions and challenged the conventional radial nature of the distribution grid by allowing bi-directional power flow. To study network behavior under such dynamic conditions, we need to have more accurate models of load and PV systems connected to the secondary side of distribution transformers.

\subsection{Distributed Generation}

There is a growing concern over climate change as well as rapid depletion of non-renewable resources. A shift away from fossil fuel based power generation will be a cogent step to build a more sustainable future. This motivation leads us towards the transition of power grids that depend increasingly on energy from renewable resources like solar and wind, the integration 
of distributed energy resources (DER), including photovoltaic (PV) arrays, energy storage, and the batteries in plug-in electric vehicles. The share of renewables has been growing significantly over the past decade. National Renewable Energy Laboratory (NREL) has projected that renewables are capable of supplying $80 \%$ of US electricity consumption by $2050[1]$.

Distributed generation refers to a variety of technologies that generate electricity at or near where it will be used, such as solar panels, combined heat and power etc. Distributed generation may serve a single structure, such as a home or business, or it may be part of a micro-grid (a smaller grid that may also be tied to the larger electricity grids), such as at a major industrial facility, a military base, or a large college campus. General Electric estimated that globally distributed power annual capacity additions will grow from $142 \mathrm{GW}$ in 2012 to $200 \mathrm{GW}$ in 2020 [2]. Among all the distributed generation sources, solar PV has the most interest. As of September 2015, 7.7 Gigawatts (GW) of solar PV based DG capacity have been installed in the U.S., and is expected to increase to as much as $20 \mathrm{GW}$ by 2020 [3]. It is estimated that among all of the solar PV installations in the US, residential solar PV will have the most significant capacity addition, from $15 \%$ in 2012 to $30 \%$ in 2020 , as shown in Figure 1.1 [4]. This indicates that the number of PV systems connected to secondaries of distribution transformers will be increasing. 


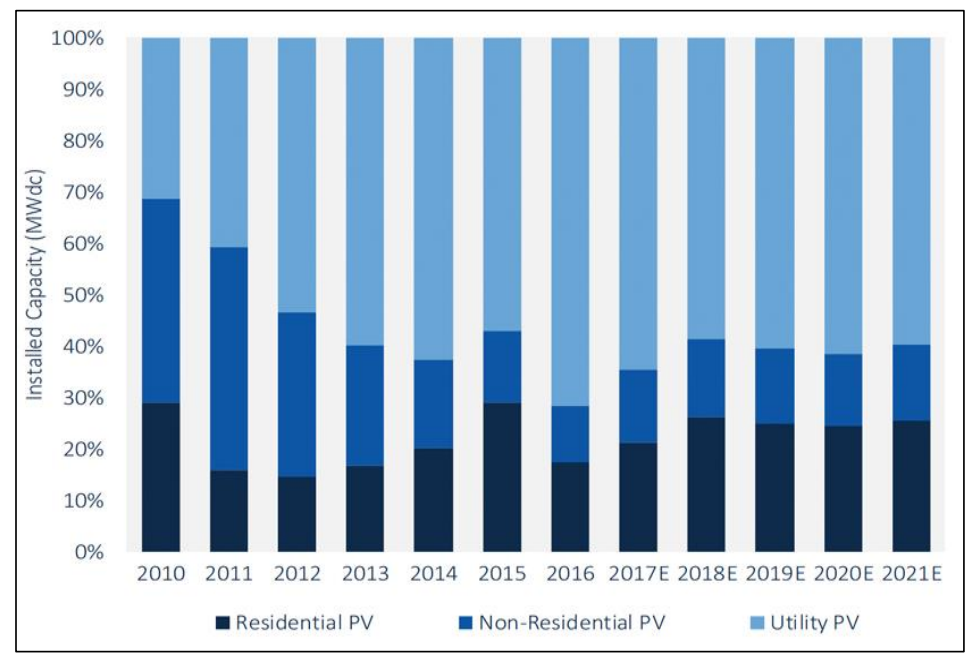

Figure 1.1: U.S. PV installation forecast by segment, 2010-2020E [4]

One of the major reasons for this is the dramatic decrease in the price of solar panels. The costs of residential and commercial PV have declined by over 70 percent since 2008 [1]. Along with the existing practices of customer-owned systems for residential PV, there is new third party ownership model in which PV systems are installed and owned by third-party companies such as SolarCity, and Sunrun [20]. These companies offer low-cost energy to residential customers that has no upfront expenditures and in exchange and customers have to purchase that PV energy for an average term of 20 years. The U.S. Energy Information Administration (EIA) data shows that third party ownerships own $44 \%$ of distributed solar capacity in the residential sector [21]. Another driving force for the growth of residential PV is the state, federal, and utility incentives for solar panel installations, as well as state renewable portfolio standards (RPS).

There are some attributes of solar energy which differentiate it from conventional sources of energy. First, Solar PV produces power intermittently as it works only when the sun is shining. Second, with the change in radiance level on the panels, which might be due to clouds, we get large power variations in short durations. So, there are a number of areas where PV could have possible impacts. First, there is a possibility that overvoltage can occur during low load conditions, particularly in locations that have large PV installed at one location which leads 
the voltage to go beyond permissible high voltage thresholds and causes the DG to trip. Second, due to changes in irradiance levels, there will be changes in PV electric power output which will directly impact the customer voltage levels. This will lead to flicker, which may be irritating to customers and may also result in malfunctioning of appliances. Third, rise or fall of voltage levels can increase the frequency of operation of On Load Tap Changers (OLTCs), voltage regulators, and switched capacitor banks, resulting in additional step-voltage changes and also leading to increases in maintenance requirements and shortening of equipment life cycles. Fourth, during the condition of low load and high PV generation, power can flow back to the grid, which can cause problems for the protection system designed for unidirectional power flow. Fifth, with the integration of PV, fault level currents will change, which directly impacts the coordination of protection equipment used. These issues have created concern among distribution engineers, regulators and researchers as to whether distribution systems will be able to accommodate very high penetration of renewables. To analyze these issues, proper modelling of distributed PV generation is required, where one should account carefully for its variability at appropriate temporal and spatial resolution, under all possible environmental conditions.

\subsection{Impact of Cloud motion on Solar PV}

Cloud motion is one of the major factors for solar irradiance variability and hence PV production variability. If there are no clouds, then the solar profile varies smoothly and predictably as the sun moves through the sky. The amount of variability due to cloud motion depends on the local climate. There are some locations that have many small clouds and/or fast wind speeds that lead to short fluctuations between clear and cloudy days. Locations that have consistent weather patterns that last over entire days have relatively low variability. Figure 1.2 displays the zones in US that have high and low solar variability. 


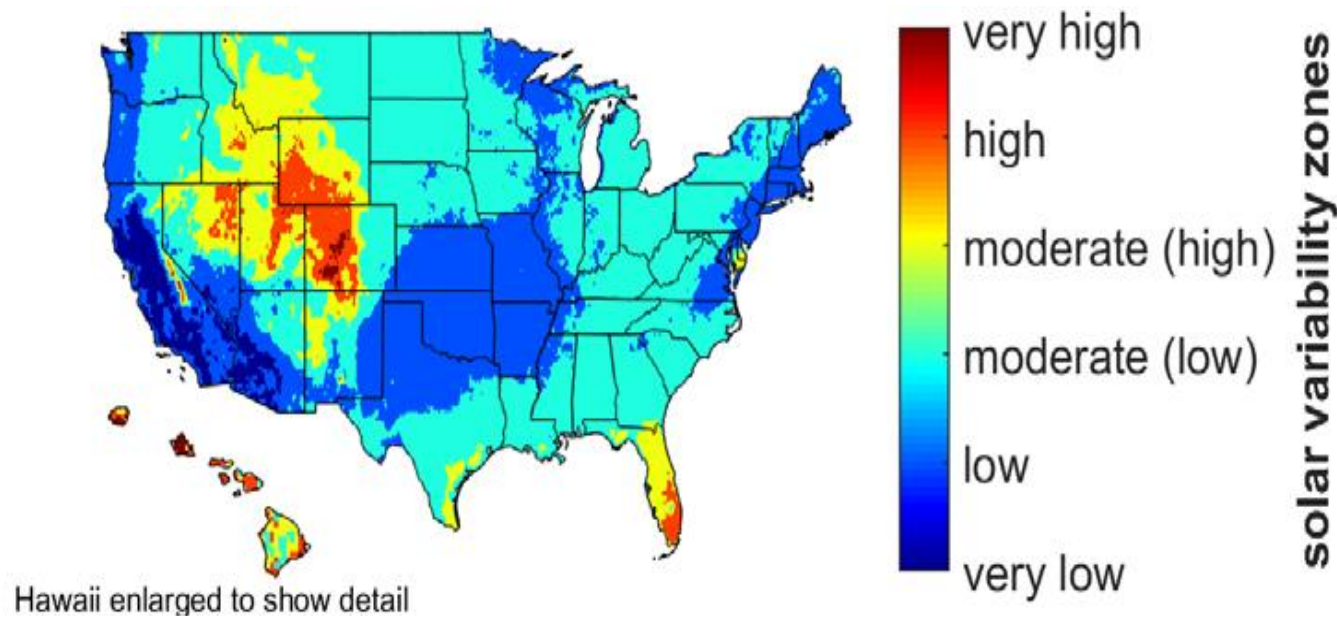

Figure 1.2: Zones showing areas of low and high solar variability [20]

The main effect of short-timescale PV variability due to cloud motion on distribution feeders is that it causes voltage fluctuations [5], [6], [7], [8], [9], [10], [11]. This voltage volatility can potentially create voltage problems since existing control devices have been implemented to manage voltage due to slow load changes. The authors in [12] and [13] studied the impacts on voltage quality due to cloud shadow movement over a feeder. In [14] the authors analyzed the impact of photovoltaic power generation capacities that were distributed over a large area. In [15] the authors investigated the voltage stability for residential customers due to high photovoltaic penetrations. In [16] the authors analyzed the voltage rise problem caused by distributed energy resources. The authors in [17] investigated the performance of fixed power factor and volt-var controllers while encountering fast irradiance fluctuations.

In previous studies the authors modeled secondary circuits with simple secondary models, using aggregated loads and generators. That is, the studies lack realistic models of loads and PV systems extending beyond distribution transformers. Combining all the loads and solar PV generation connected to a distribution transformer at one location can lead to significant errors. As a result, the locations and/or estimated costs for mitigating foreseeable issues may not be correct. In this thesis we consider detailed secondary models to achieve increased analysis accuracy, analyzing the impact of PV resources at each individual customer location. 


\subsection{Objective}

The above discussion highlights two important aspects to analyze the impact of Solar PV on distribution systems,

- Spatial and temporal analysis of distribution systems with high PV penetration under different weather conditions and system states.

- Comparison of system parameters under a conventional simple secondary model and proposed detailed secondary model.

\subsection{Organization of the thesis}

The rest of the thesis is organized into four chapters. A brief description of the chapters is given below:

Chapter 2: This chapter covers the details of the distribution network employed for the study. Along with that, two analysis approaches (i.e. traditional simple model and detailed secondary model) will also be discussed. This chapter also discusses the network modelling and simulation approach used in the Distributed Engineering Workstation (DEW) software. Since we will be using a cloud motion simulator tool of DEW, the concepts related to that will be highlighted in this chapter.

Chapter 3: In this chapter, through a series of case studies, the advantages of using detailed secondary and simple secondary circuits will be discussed. This chapter compares the impact of a cloud motion simulator on detailed secondary and simple secondary circuit analysis results. Along with that we will discuss the inferences from the results obtained, and justify the differences in results obtained from the two analysis/modelling approaches. We will also analyze the dependence of voltage variation analysis errors with number of customers connected to the distribution transformer. 
Chapter 4: This chapter summarizes the work presented in the thesis and provides recommendations for future research using detailed secondary models. 


\section{Chapter 2: Problem setup}

The distribution system is divided into primary and secondary distribution. As considered here the primary distribution comprises the high voltage delivery portion of the distribution system, and exists on the high voltage side of distribution transformers. The secondary distribution comprises the customer level or low voltage delivery portion of the distribution system, and exists on the low voltage side of distribution transformers. A single-line diagram of a typical distribution system is shown in Figure 2.1 .

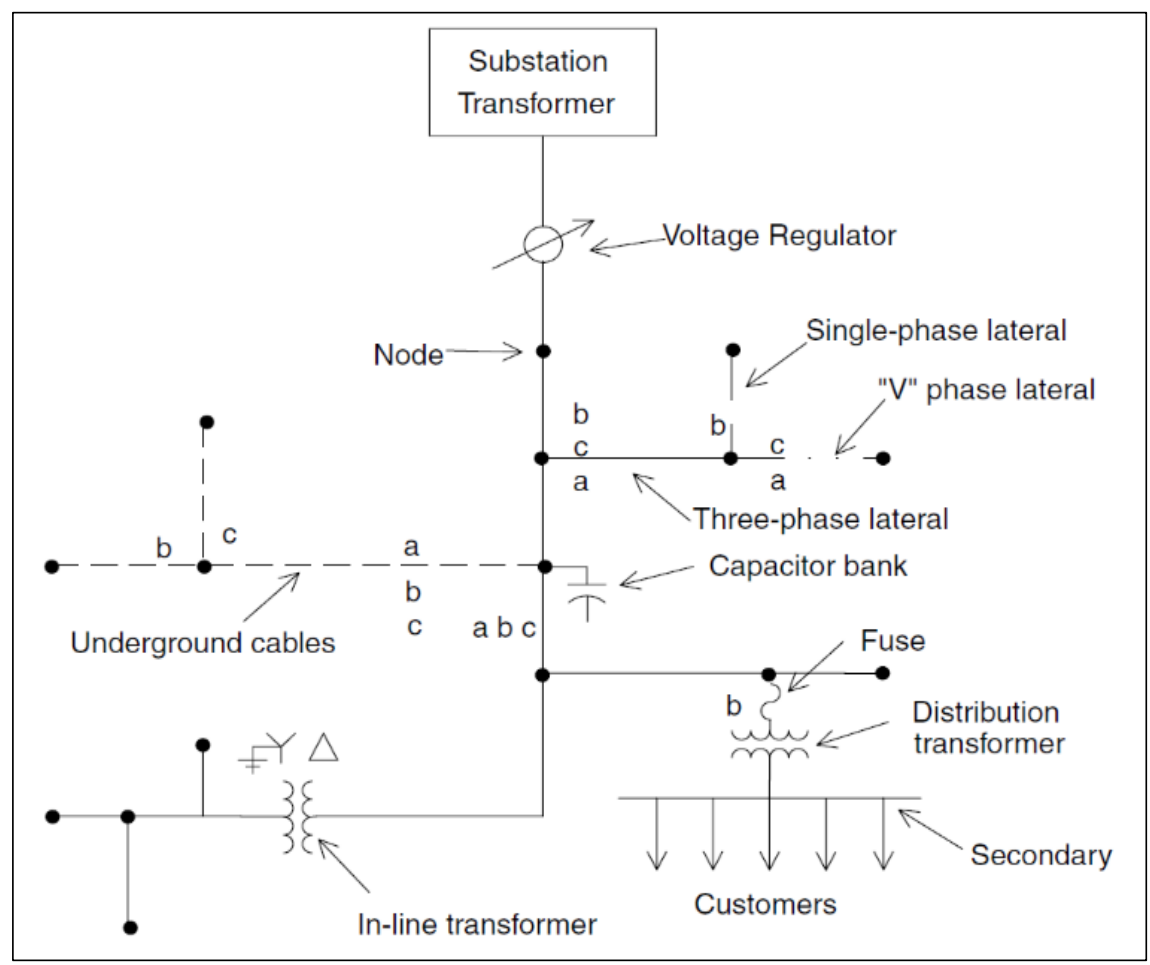

Figure 2.1: Single line diagram of distribution system [6]

2.1 Introduction on the two analysis approaches being compared (Traditional simple model;

Detailed secondary model)

The difference between simple secondary and detailed secondary models will now be explained. Traditionally when we model the primary distribution we model each element as it exists. But traditionally when we model secondary distribution on the low voltage side of a distribution transformer, all customer loads, PV generators, and others are aggregated and 
represented as a single load and a single power source, which here will be a PV generator. Traditionally conductors in secondary distribution are not modeled. Here we will refer to such a model as a simple secondary model. Figure 2.2 illustrates a simple secondary model. Monitor Points, which are measurement points associated with the Cloud Motion Simulator (CMS), shown in Figure 2.2 are used in this study.

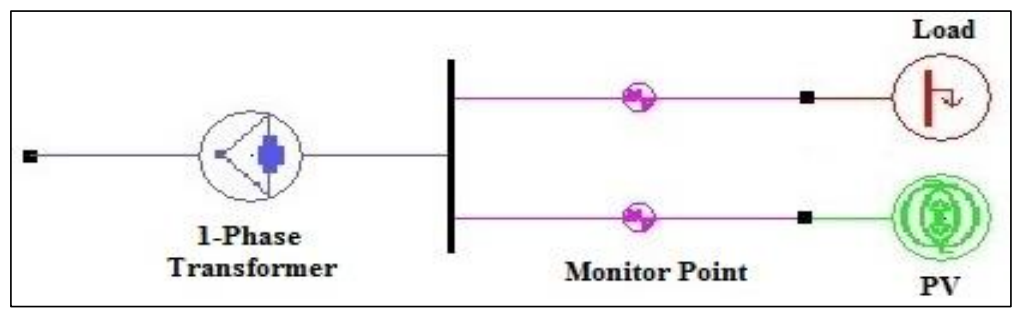

Figure 2.2: Simple secondary model example

Another model of the secondary system is considered here, referred to as a detailed secondary model. In a detailed secondary model each customer load, each PV generator, and each secondary conductor is modeled as it exists.

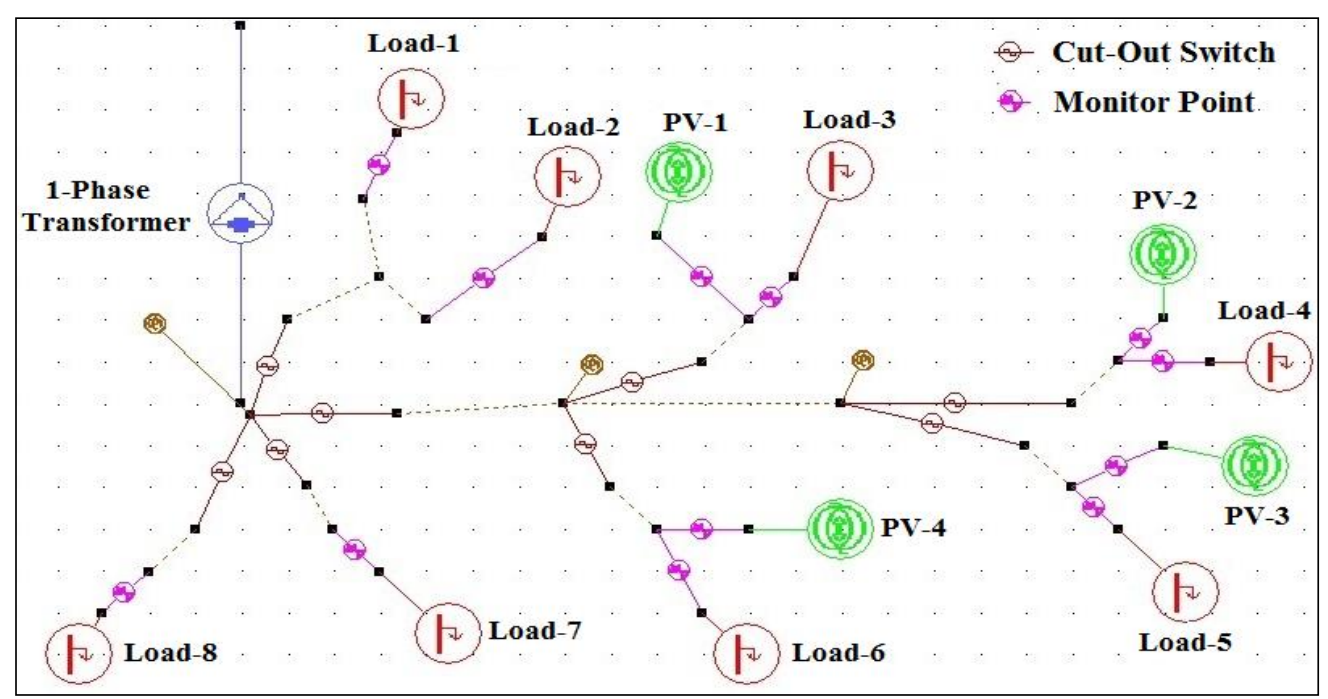

Figure 2.3: Detailed secondary model example

Figure 2.3 illustrates a detailed secondary model. In Figure 2.3 the sum of the eight customer loads and the sum of the four PV generations could be used to create an aggregate load and PV generator corresponding to the simple secondary model of Figure 2.2. But secondary conductors are not modeled in the simple secondary model at all. In the detailed secondary 
model, the secondary conductors are represented by the dotted lines in Figure 2.3. Simulation results from secondary circuit models like those of figures 4 and 5 are compared in the next section.

2.2 Details of distribution network employed for study

The distribution feeder used for the simulation, which is an actual distribution feeder, has a voltage level of $20.78 \mathrm{kV}$ and consists of 1489 loads and 248 PV generators. The feeder with the detailed secondary models is shown in Figure 2.4. In figures 6 and 7 the brown lines represent 3-phase lines, the green components represent PV generators, and the red components represents load buses.

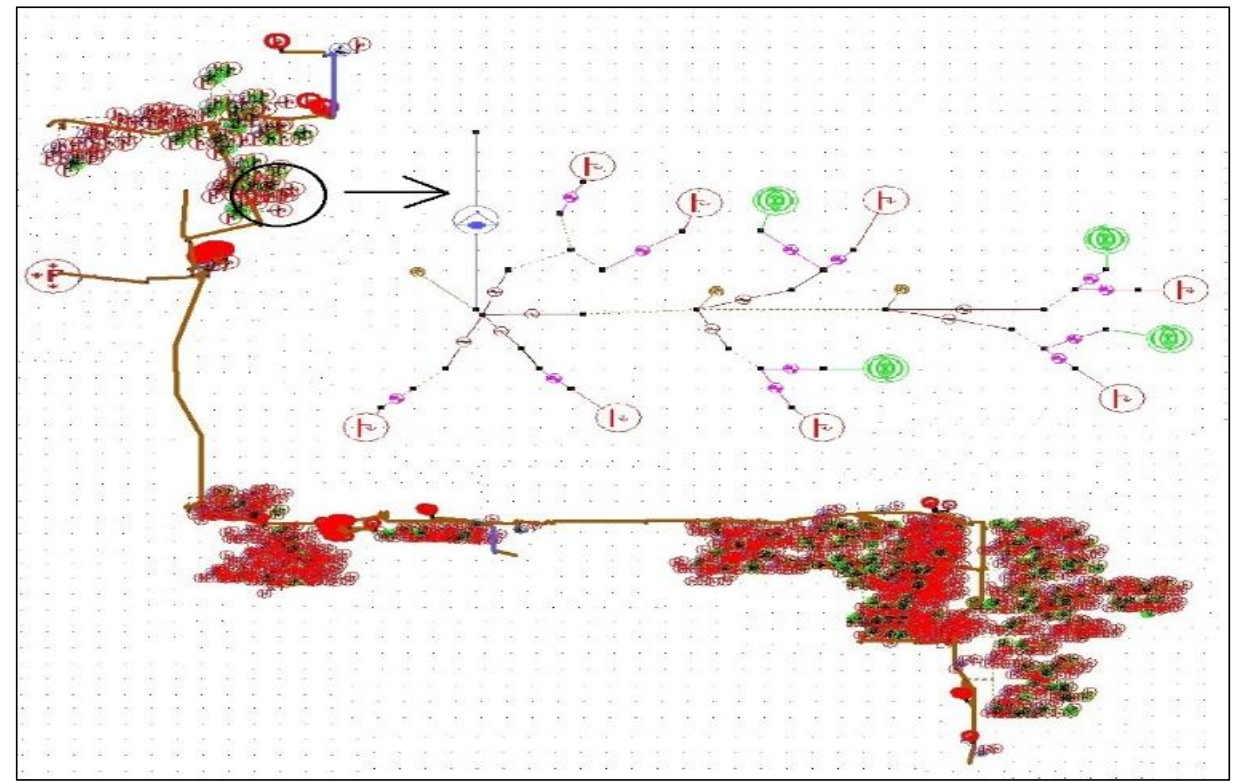

Figure 2.4: Distribution feeder with detailed secondary models, with a zoom-in or blowup of one detailed secondary model illustrated

There are different secondary system configurations of loads and PV systems for each distribution transformer, where the arrow in Figure 2.4 points to a blowup of one of the detailed secondary models. 


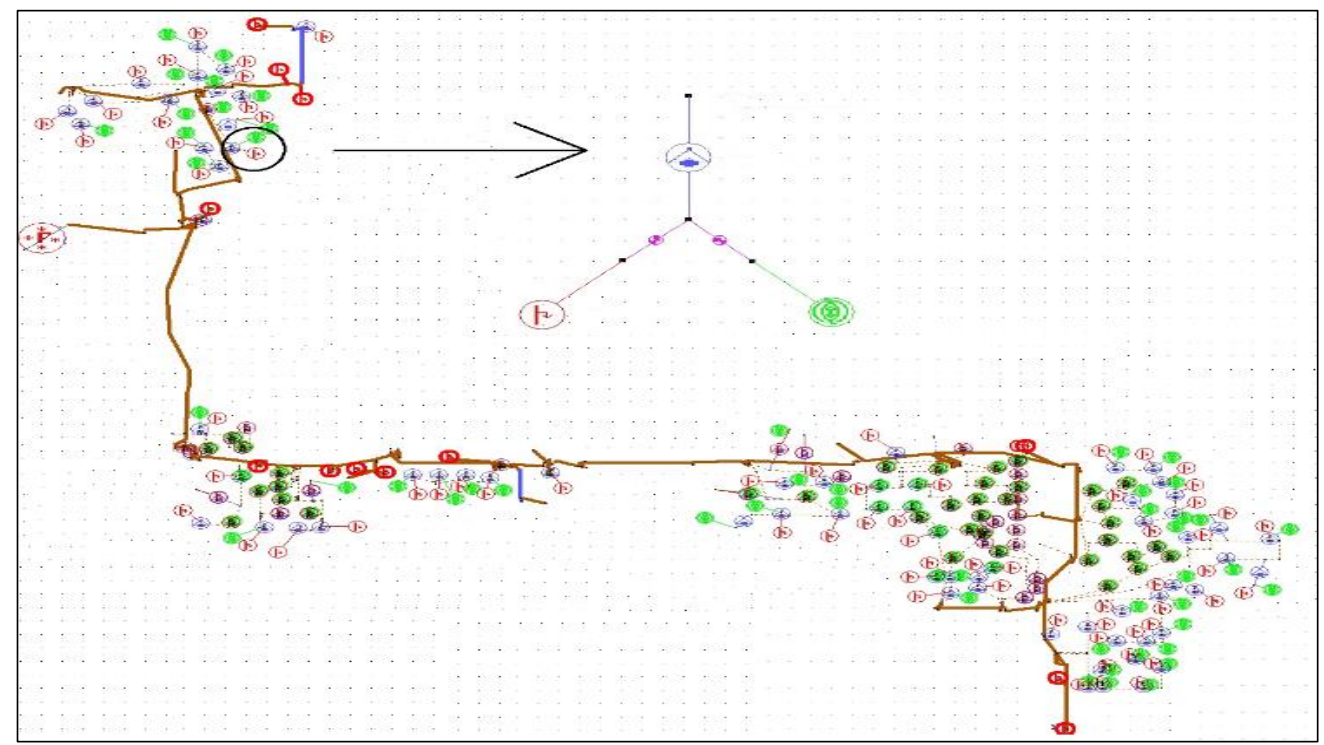

Figure 2.5: Distribution feeder with simple secondary models, where the same model is used for each secondary

Figure 2.5 uses the same primary distribution feeder as that of Figure 2.4, but the circuit of Figure 2.5 employs simple secondary models derived from their corresponding detailed secondary models found in Figure 2.4. In Figure 2.5 there are 145 loads and 95 PV generators represented, which will be compared with the detailed model of Figure 2.4 where there are 1489 loads and 248 PV generators.

\subsection{Cloud Motion Simulator}

Many current studies which analyze the impact of PV generation on the distribution system use steady state analysis employing a step change (i.e., one power flow is run for the initial state of a system and another power flow for the final state, and the difference between the two states is calculated). In the step change calculations, the output of the PV generator changes from an initial to a final value instantaneously as clouds cover the distribution feeder. To analyze the system more accurately, quasi- steady state analysis may be performed, in which a series of studies are run over a time frame with some sample rate (i.e. one second, one minute, one hour), and power flow is run for each sample time. Thus, the quasi steadystate study evaluates a time-series of impacts. 
The CMS simulates irradiance fluctuations due to cloud shadows and the consequent voltage changes [18]. To perform the more accurate cloud motion simulation, detailed meteorological data is required. The CMS parameters used in this study are shown in Table 2.1.

Table 2.1: Cloud motion simulator input parameters

\begin{tabular}{|c|c|}
\hline Parameter & Parameter Description \\
\hline$P_{1}$ & Number of clouds passing over the circuit \\
\hline$P_{2}$ & The direction of the cloud motion \\
\hline$P_{3}$ & Speed of cloud shadows \\
\hline$P_{4}$ & Time between successive clouds \\
\hline$P_{5}$ & $\begin{array}{r}\text { Woints for a curve specifying percent rate of change of PV } \\
\text { generation as a cloud shadow either covers or uncovers a PV } \\
\text { generator [18] }\end{array}$ \\
\hline$P_{6}$ & $\begin{array}{r}\text { Pond } \\
\hline\end{array}$ \\
\hline
\end{tabular}

In the CMS, as cloud shadows moves over a PV generator, the generation changes as per a piecewise linear curve specified in parameter 6 [18]. Figure 2.6 illustrates the change in generation at different points as cloud covers the PV generator and change of generation is based on the decay and recovery rates which are user defined. In Figure 2.6, the darkest blue color shading region represents $20 \%$ generation and the unshaded region represents $100 \%$ generation. 


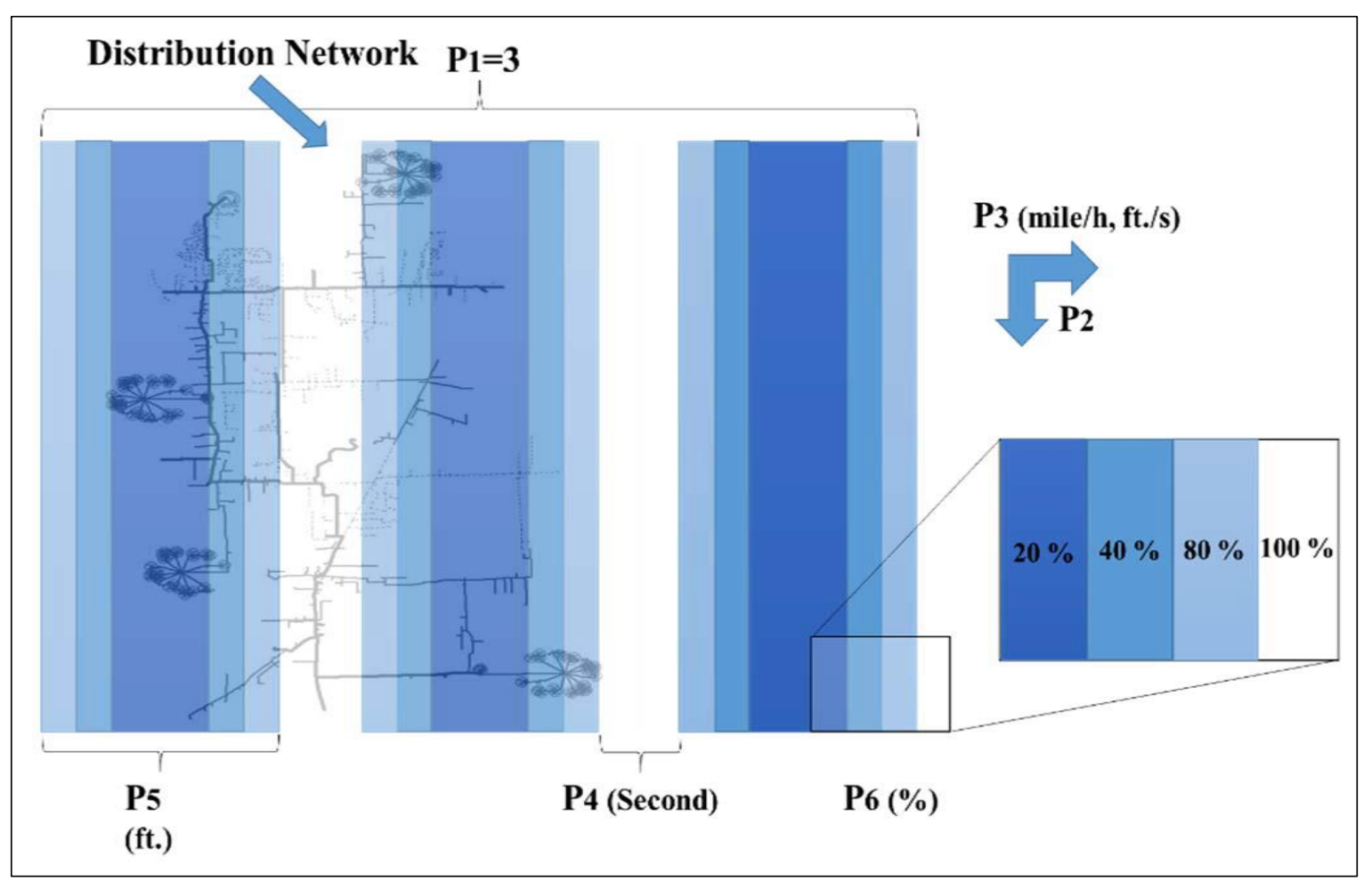

Figure 2.6: Cloud motion simulator parameters [18]

The CMS uses a quasi-steady state power flow with a one second step size. At each second of the simulation the PV generator, which cloud shadows move over, are identified, and their outputs are adjusted. The simulation is performed by considering the $(x, y)$ coordinates of the PV generators and the $(x, y)$ coordinates of the simulated cloud shadows, which change over the simulation time. At each second of the simulation the CMS detects the affected PV inverters and updates their output power accordingly. Figure 2.7 illustrates how the CMS performs the QSS simulation in collaboration with a power flow analysis. 


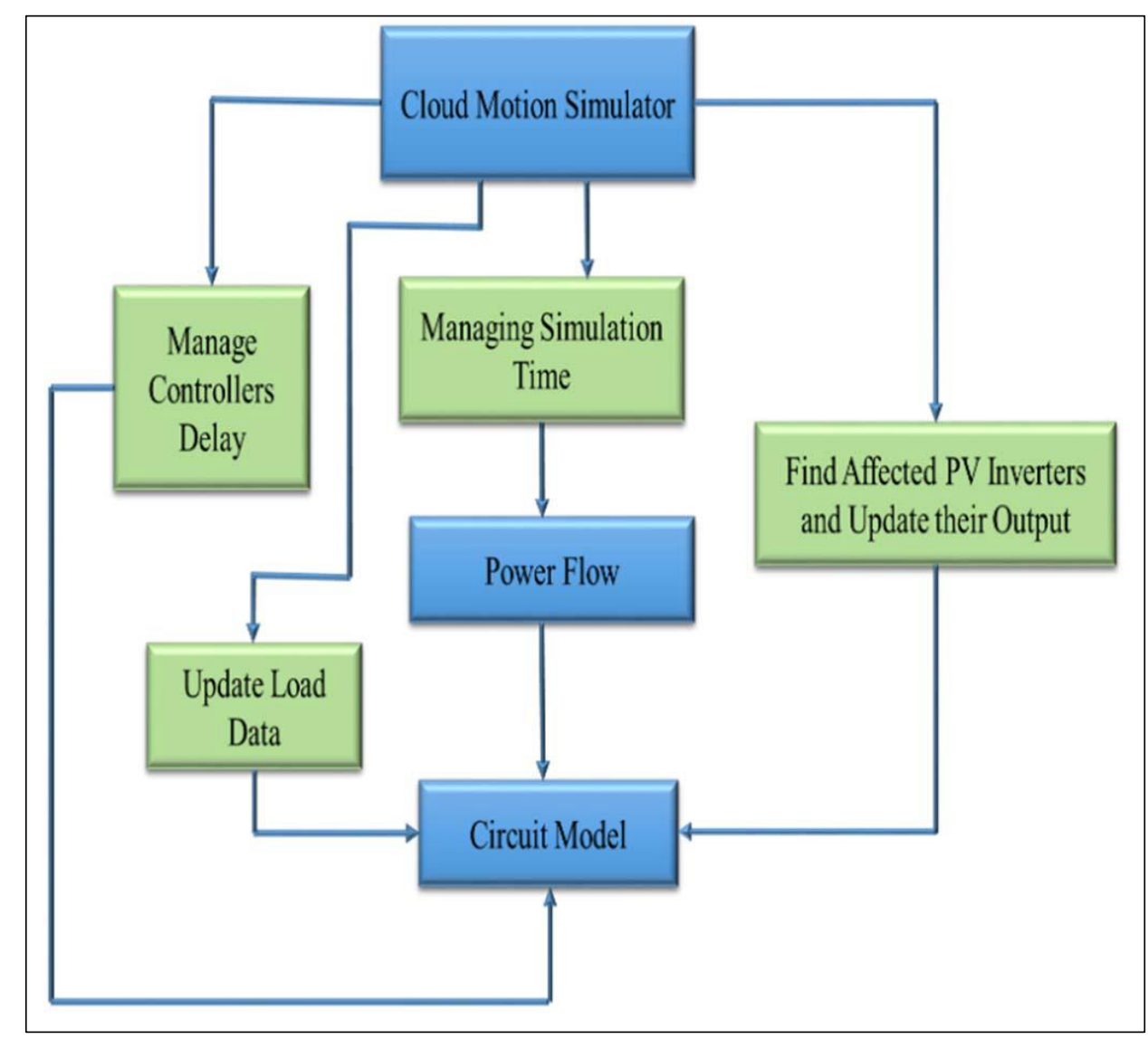

Figure 2.7: Cloud motion simulator interaction with power flow analysis [18]

In the simulation considered here the cloud speed is set equal to 15 miles/hour and the direction of cloud movement is North-to-South. The number of clouds is set to 10 with an interval of 10 seconds between two subsequent clouds. The CMS is run on both the simple and detailed secondary circuit models. 


\section{Chapter 3: Case Study and Simulation Results}

A Cloud Motion Simulator (CMS) has been used in this study to study the voltage variations at distribution network nodes due to cloud shadow motion. As clouds cover the PV generators, voltage variations occur and locations with the highest voltage variations are compared for the simple and detailed secondary models. Differences in voltage changes between the simple and detailed secondary circuits are also compared, and parameterized by the number of customers associated with the secondary models.

3.1 Comparison of cloud motion impact analysis with simple secondary and detailed secondary modeling

The CMS is run on both the simple and detailed secondary circuit models, and the five locations with the highest voltage decrease rates (i.e. voltage change over one second) in both circuits are identified. Identified locations from the two simulations are shown in Figure 3.1.

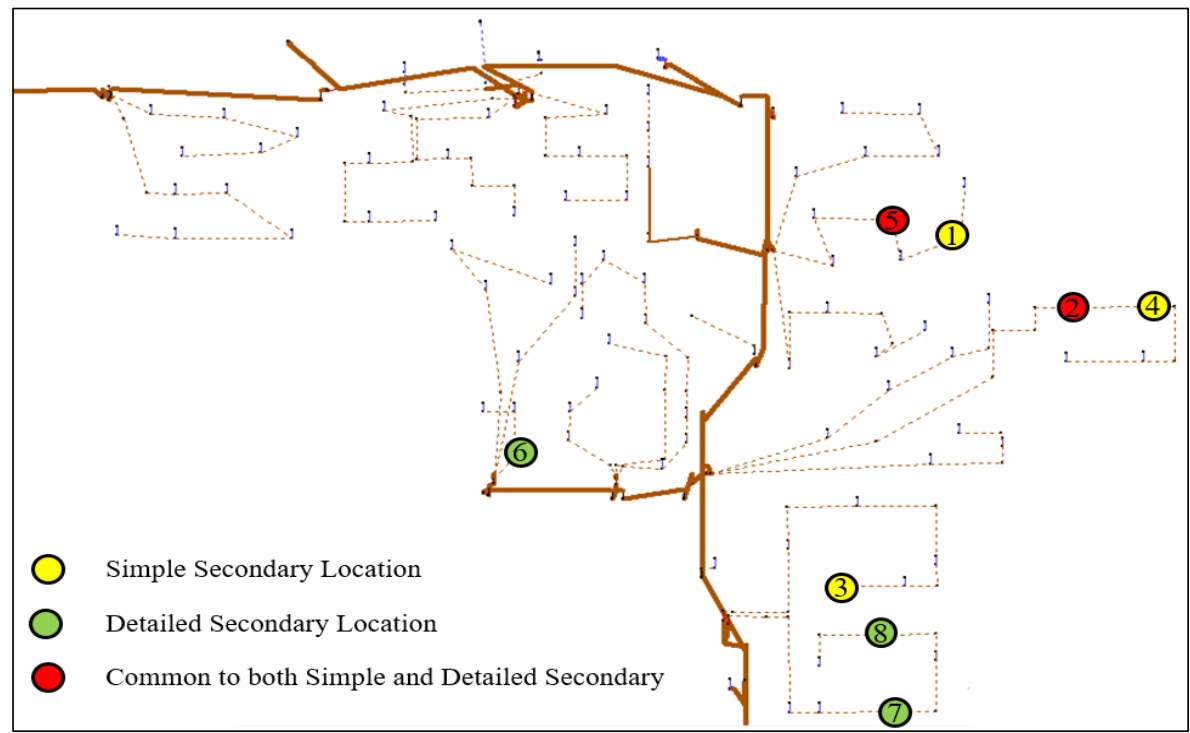

Figure 3.1: Locations with highest decrease in voltage over one second for simple and detailed secondary models.

Yellow circles represent locations where simple secondary models predict the highest voltage decrease, green circles represent locations where the detailed secondary models predict the 
highest voltage decrease, and red circles represent locations where the two different models agree.

From Figure 3.1 it may be observed that locations with the highest voltage decrease rates vary significantly for the simple and detailed modeling approaches. The magnitude of voltage decrease rates for the locations with the highest voltage changes in both models are shown in Table 3.1.

Table 3.1: Rate of voltage decrease for simple and detailed secondary circuits for locations with highest changes

\begin{tabular}{|c|c|c|c|}
\hline \multicolumn{2}{|c|}{ Simple Secondary } & \multicolumn{2}{c|}{ Detailed Secondary } \\
\hline $\begin{array}{c}\text { Location } \\
\text { Number }\end{array}$ & Rate of Voltage Change (V/sec) & $\begin{array}{c}\text { Location } \\
\text { Number }\end{array}$ & Rate of Voltage Change (V/sec) \\
\hline 1 & -0.420 & 2 & -0.275 \\
\hline 2 & -0.359 & 5 & -0.265 \\
\hline 3 & -0.340 & 6 & -0.274 \\
\hline 4 & -0.338 & 7 & -0.256 \\
\hline 5 & -0.337 & 8 & -0.253 \\
\hline
\end{tabular}

From Table 3.1 the magnitudes of the highest voltage decrease rates in both models are quite different. Table 3.1 shows that the voltage decrease rates from the simple secondary models are larger. When clouds move over the distribution feeder, the output of PV connected to the secondary of distribution transformers changes. In the detailed secondary circuit, the geographical diversity of the PV systems is considered, and not all PV generators are affected at the same time as in the simple secondary circuit. This leads to significant differences in results to which we will refer to as errors in what follows. Table 3.2 evaluates the voltage decrease rate over-estimation and resulting errors of the simple models.

From Table 3.2 it may be seen that the voltage error, or voltage change-overestimation, from the simple secondary models can be very high, and its graphical representation is illustrated in Figure 3.2. 
Table 3.2: Errors in rate of voltage decrease for simple models and detailed secondary models

\begin{tabular}{|c|c|c|c|}
\hline $\begin{array}{c}\text { Location } \\
\text { Number }\end{array}$ & $\begin{array}{c}\text { Rate of Voltage Decrease in } \\
\text { Simple Secondary (V/sec) }\end{array}$ & $\begin{array}{c}\text { Rate of Voltage Decrease } \\
\text { in Detailed Secondary } \\
(\mathrm{V} / \mathrm{sec})\end{array}$ & $\begin{array}{c}\text { Percentage } \\
\text { Voltage Error }\end{array}$ \\
\hline 2 & -0.359 & -0.275 & 30.6 \\
\hline 5 & -0.337 & -0.265 & 27.1 \\
\hline 6 & -0.305 & -0.274 & 11.4 \\
\hline 7 & -0.318 & -0.256 & 24.4 \\
\hline 8 & -0.298 & -0.253 & 17.5 \\
\hline
\end{tabular}

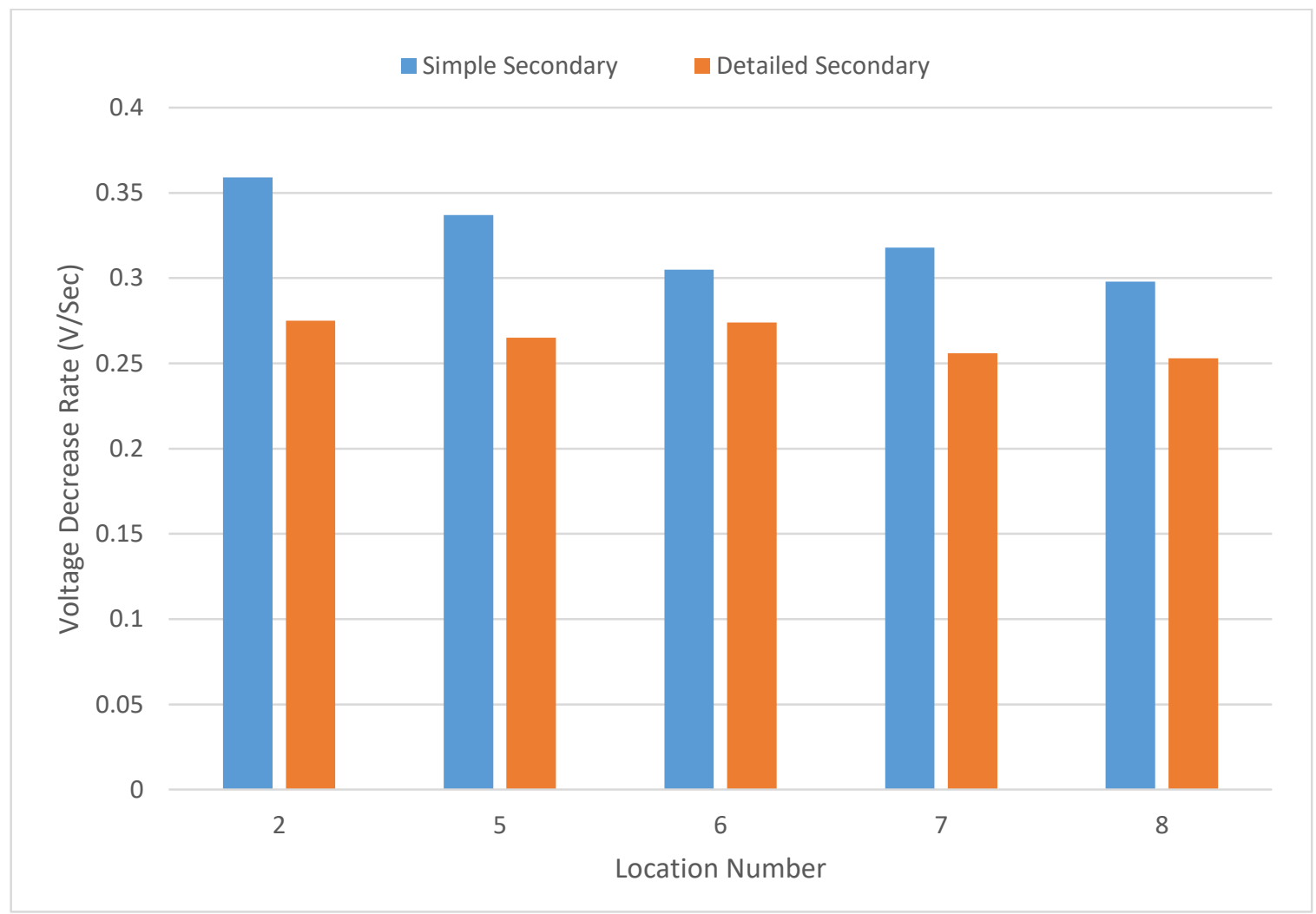

Figure 3.2: Absolute value of voltage decrease rate for simple and detailed secondary models

Dynamic changes in net load both from distributed load and generation causes a corresponding transient, or change in voltage, referred to as voltage flicker [18]. Electrical equipment and/or humans can tolerate only certain amounts of flicker, so detailed analysis of flicker values is required. As flicker values depend on the magnitude, duration, and frequency of the voltage, it can be impacted by the variability of PV output due to cloud 
motion. In this study we used the CMS for calculating the flicker values. The CMS computes the short-term flicker severity index based on the IEEE 1453-2015 standard [18]. From Table 3.3 it may be seen that the flicker error from the simple secondary models can be very high and its graphical representation can be seen in Figure 3.3.

Table 3.3: Flicker value comparisons for simple and detailed secondary circuits

\begin{tabular}{|c|c|c|c|}
\hline $\begin{array}{c}\text { Location } \\
\text { Number }\end{array}$ & $\begin{array}{c}\text { Flicker in Simple Secondary } \\
\text { (Pst value) }\end{array}$ & $\begin{array}{c}\text { Flicker in Detailed Secondary } \\
\text { (Pst value) }\end{array}$ & $\begin{array}{c}\text { Percentage } \\
\text { Flicker Error }\end{array}$ \\
\hline 2 & 0.278 & 0.266 & 4.51 \\
\hline 5 & 0.283 & 0.245 & 15.51 \\
\hline 6 & 0.263 & 0.252 & 4.37 \\
\hline 7 & 0.321 & 0.248 & 29.44 \\
\hline 8 & 0.325 & 0.254 & 27.95 \\
\hline
\end{tabular}

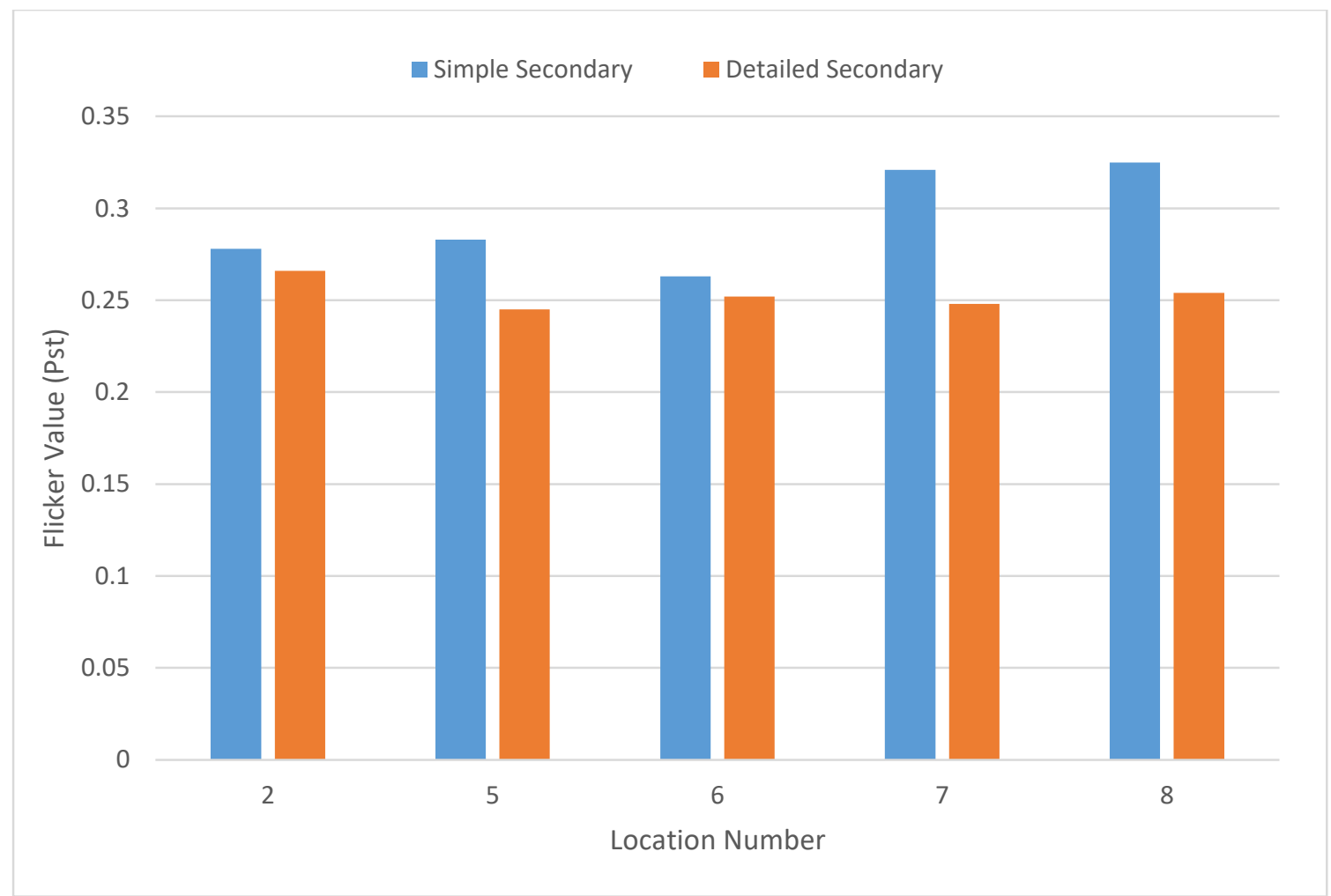

Figure 3.3: Flicker values for simple secondary models and detailed secondary models

3.2 Analysis for dependence of voltage variation estimation error with different loading (Maximum/Minimum Load) and number of connected customers

In the next step, the idea is to analyze whether locations with different numbers of customers will have any impact on the voltage decrease rate level. To understand this, the detailed 
analysis at the extremes of the circuit is required. An appropriate averaged load profile for each load class (commercial and residential) was obtained from a utility in the feeder's geographical region. The load profile used for analysis is shown in Figure 3.4.

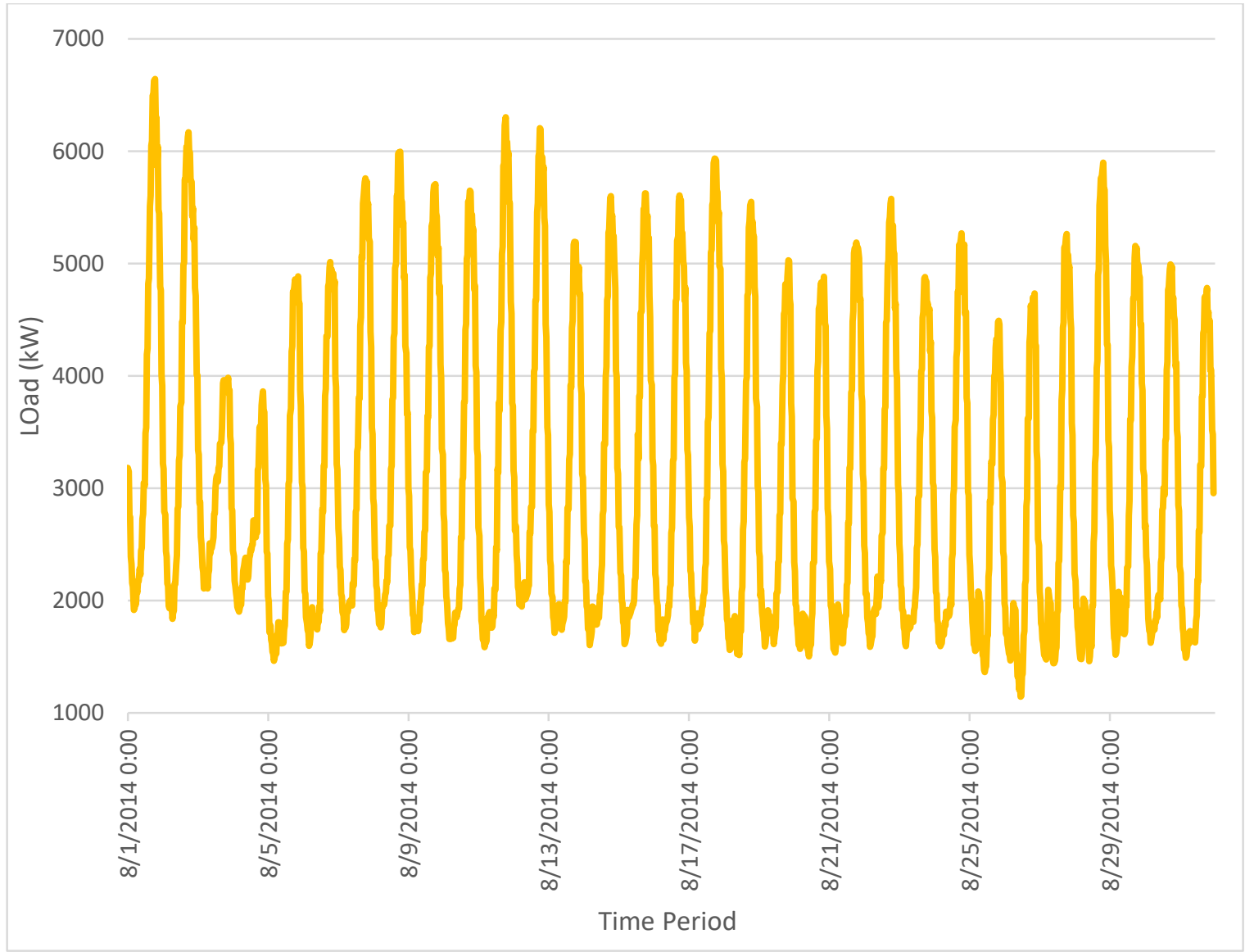

Figure 3.4: Load profile for simple secondary and detailed secondary models In what follows, two extreme scenarios are considered, maximum load (6641 kW) and minimum load (1144kW), and voltage errors associated with the number of loads attached to the secondary are investigated. In the scenarios locations are selected with different numbers of customers on the secondary, varying from 2 to 24 customers. Mean values of rate of voltage decrease and the locations with the maximum value of rate of voltage decrease, along with locations with the minimum value of rate of voltage decrease, are investigated. The PV penetration for each secondary is also considered, which will provide insight into the way PV penetration impacts differences between the simple and detailed models. PV penetration 
values presented in section 3.2.1 and section 3.2.2 are defined as the ratio of total PV generation to total load connected to a specific distribution transformer.

\subsubsection{Scenario 1- Maximum Load}

In the first scenario we consider the maximum load on the feeder, $6641 \mathrm{~kW}$, and the simulation was run at that corresponding time period, as shown in Figure 3.4. The CMS results for locations with the maximum voltage decrease rates are shown in Table 3.4. The maximum voltage decrease rate refers to that of the detailed secondary circuit where we have $\mathrm{N}$ customers to compare with the simple secondary circuit results, and we choose the customer in the detailed model that has the maximum decrease rate. That is, if there are 4 customers in a detailed model, then the voltage decrease rate value of the detailed secondary column refers to maximum decrease rate value among 4 customers.

Table 3.4: Percentage voltage decrease errors for simple models and detailed secondary models

\begin{tabular}{|c|c|c|c|c|}
\hline $\begin{array}{c}\text { Number } \\
\text { of Loads }\end{array}$ & $\begin{array}{c}\text { Percentage } \\
\text { PV } \\
\text { Penetration }\end{array}$ & $\begin{array}{c}\text { Rate of Voltage } \\
\text { Decrease in Simple } \\
\text { Secondary } \\
(\mathrm{V} / \mathrm{sec})\end{array}$ & $\begin{array}{c}\text { Rate of Voltage } \\
\text { Decrease in Detailed } \\
\text { Secondary } \\
(\mathrm{V} / \mathrm{sec})\end{array}$ & $\begin{array}{c}\text { Percentage } \\
\text { Voltage } \\
\text { Error }\end{array}$ \\
\hline 2 & 0 & -0.02433 & -0.00039 & 98.41 \\
\hline 4 & 40.75 & -0.02679 & -0.11577 & -332.09 \\
\hline 6 & 47.71 & -0.07188 & -0.16500 & -129.53 \\
\hline 8 & 0 & -0.02678 & -0.00033 & 98.77 \\
\hline 10 & 0 & -0.09705 & -0.00342 & 96.48 \\
\hline 12 & 40.90 & -0.40978 & -0.24746 & 39.61 \\
\hline 14 & 25.23 & -0.22132 & -0.21390 & 3.35 \\
\hline 16 & 28.54 & -0.44679 & -0.29646 & 33.65 \\
\hline 18 & 19.85 & -0.30032 & -0.11149 & 62.88 \\
\hline 20 & 0 & -0.25643 & -0.00506 & 98.03 \\
\hline 24 & 40.75 & -0.36678 & -0.18353 & 49.96 \\
\hline
\end{tabular}

The absolute value of errors associated with the maximum voltage decrease rates versus number of customers on the secondary are illustrated in Figure 3.5. 


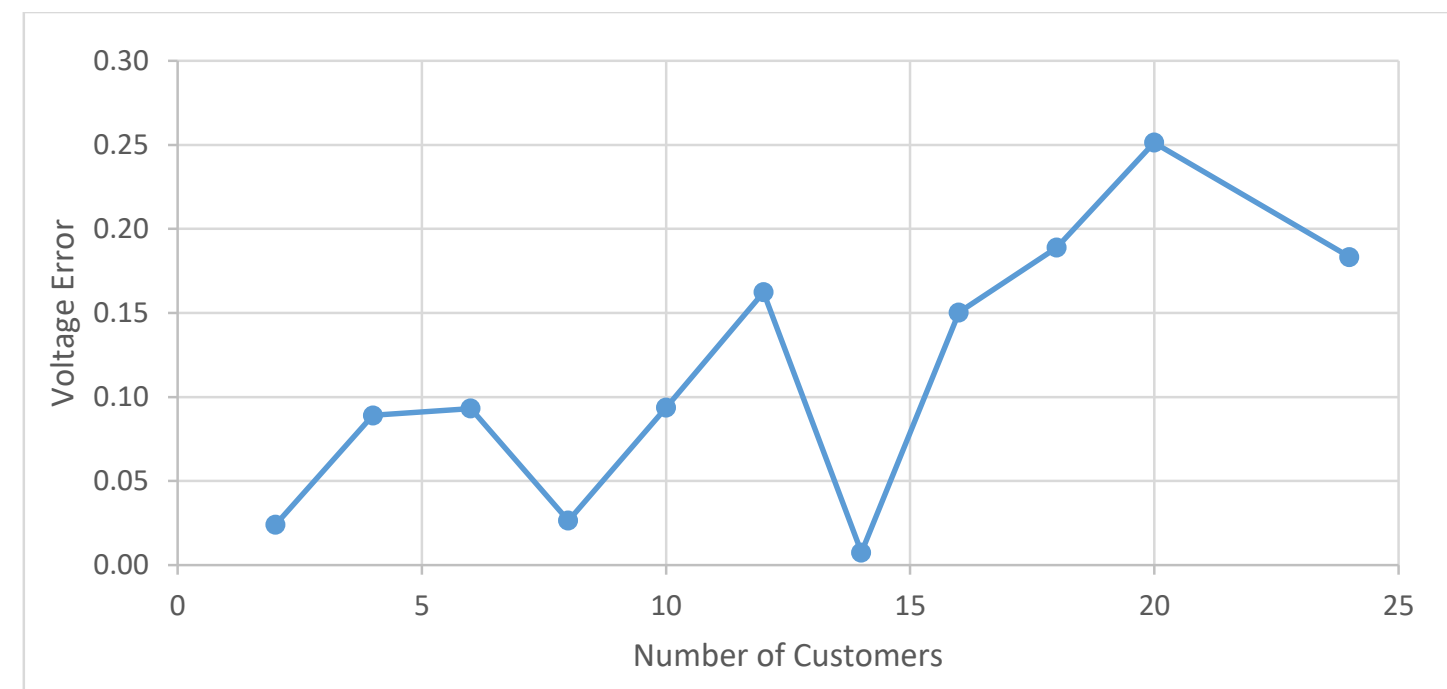

Figure 3.5: Absolute value of the errors associated with maximum voltage decrease rate between the simple and detailed models versus number of secondary customers

The variations of percentage errors for the maximum voltage decrease rates, along with associated PV penetration values, versus number of customers on the secondary, are illustrated in Figure 3.6.

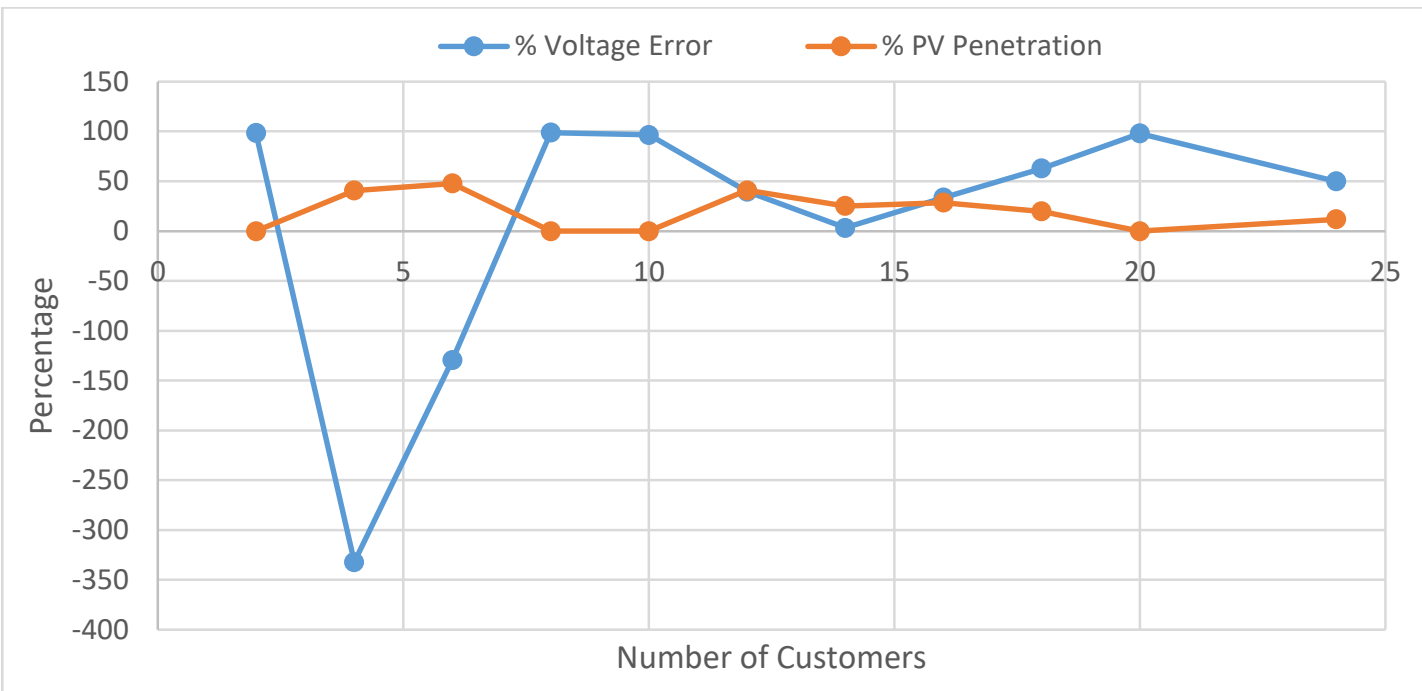

Figure 3.6: Percentage errors in prediction of maximum voltage decrease rates, along with associated PV penetration levels, versus number of secondary customers

The cloud motion simulation results for locations with the mean voltage decrease rates are shown in Table 3.5 . 
Table 3.5: Percentage voltage decrease errors for simple models and detailed secondary models

\begin{tabular}{|c|c|c|c|c|}
\hline $\begin{array}{c}\text { Number } \\
\text { of Loads }\end{array}$ & $\begin{array}{c}\text { Percentage } \\
\text { PV }\end{array}$ & $\begin{array}{c}\text { Rate of Voltage } \\
\text { Decrease in Simple } \\
\text { Secondary } \\
(\mathrm{V} / \mathrm{sec})\end{array}$ & $\begin{array}{c}\text { Rate of Voltage } \\
\text { Decrease in Detailed } \\
\text { Secondary } \\
(\mathrm{V} / \mathrm{sec})\end{array}$ & $\begin{array}{c}\text { Percentage } \\
\text { Voltage } \\
\text { Error }\end{array}$ \\
\hline 2 & 0 & -0.02433 & -0.00039 & 98.41 \\
\hline 4 & 40.75 & -0.02679 & -0.05540 & -106.75 \\
\hline 6 & 47.71 & -0.07188 & -0.11185 & -55.61 \\
\hline 8 & 0 & -0.02678 & -0.00033 & 98.77 \\
\hline 10 & 0 & -0.09705 & -0.00340 & 96.49 \\
\hline 12 & 40.90 & -0.40978 & -0.09773 & 76.15 \\
\hline 14 & 25.23 & -0.22132 & -0.05968 & 73.04 \\
\hline 16 & 28.54 & -0.44679 & -0.11410 & 74.46 \\
\hline 18 & 19.85 & -0.30032 & -0.02349 & 92.18 \\
\hline 20 & 0 & -0.25643 & -0.00504 & 98.04 \\
\hline 24 & 40.75 & -0.36678 & -0.04388 & 88.04 \\
\hline
\end{tabular}

The absolute value of errors associated with the mean voltage decrease rates versus number of customers on the secondary are illustrated in Figure 3.7.

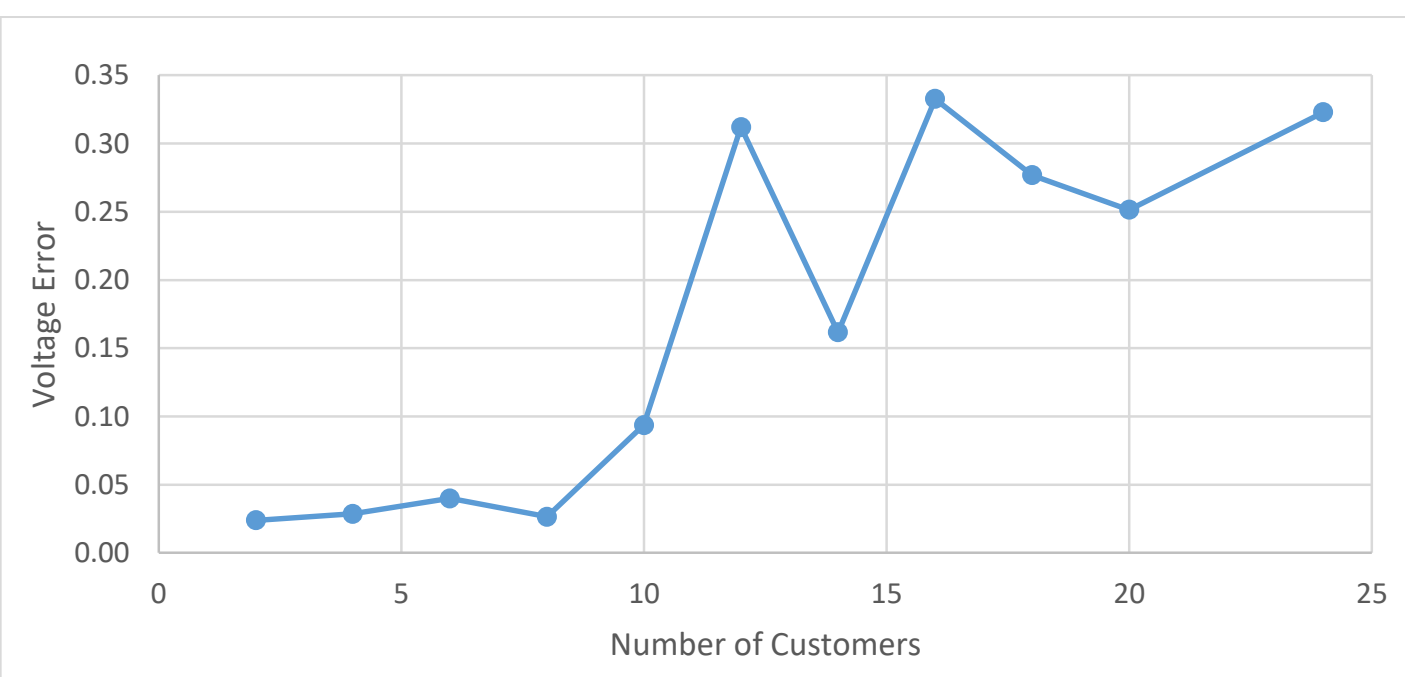

Figure 3.7: Absolute value of the errors associated with mean voltage decrease rate between the simple and detailed models versus number of secondary customers

The variations of percentage errors for the mean voltage decrease rates, along with associated PV penetration values, versus number of customers on the secondary, are illustrated in Figure 3.8. 


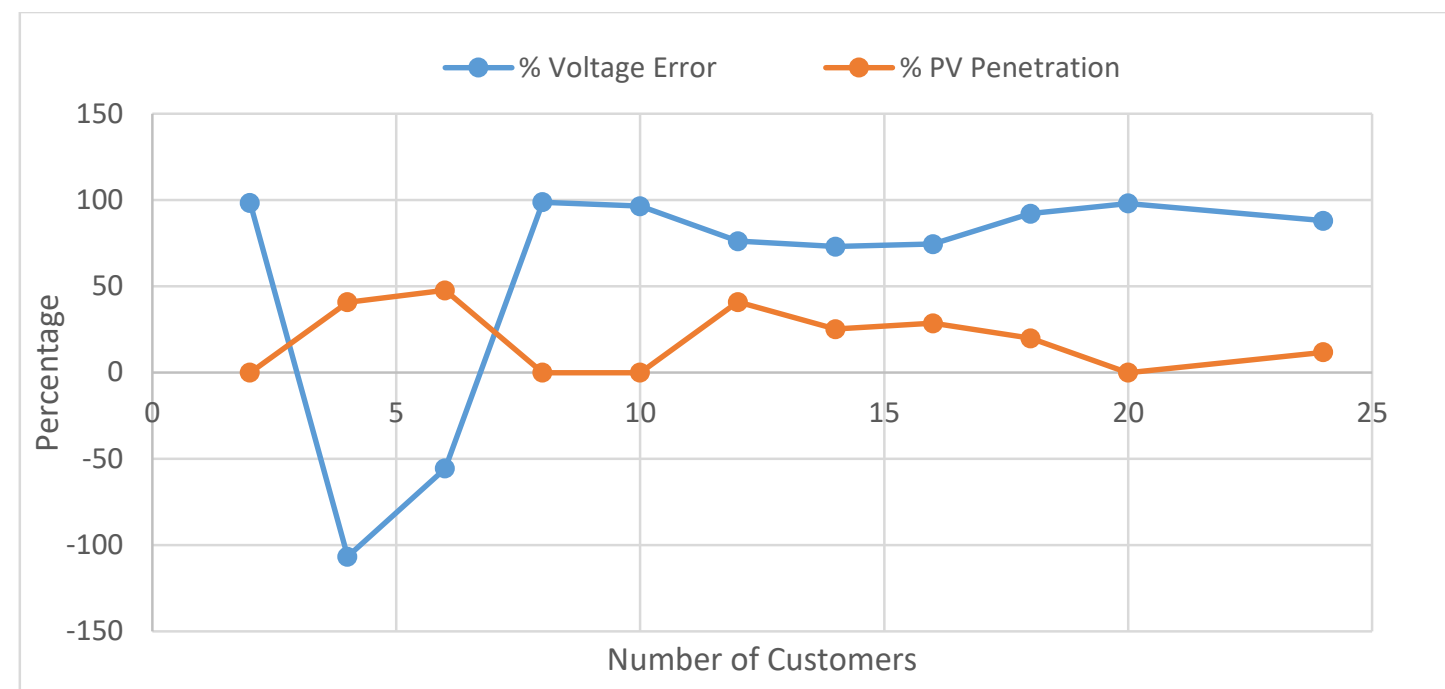

Figure 3.8: Percentage errors in prediction of mean voltage decrease rates, along with associated PV penetration levels, versus number of secondary customers

The cloud motion simulation results for locations with the minimum voltage decrease rates are shown in Table 3.6.

Table 3.6: Percentage voltage decrease errors for simple models and detailed secondary models

\begin{tabular}{|c|c|c|c|c|}
\hline $\begin{array}{c}\text { Number } \\
\text { of Loads }\end{array}$ & $\begin{array}{c}\text { Percentage } \\
\text { PV } \\
\text { Penetration }\end{array}$ & $\begin{array}{c}\text { Rate of Voltage } \\
\text { Decrease in Simple } \\
\text { Secondary } \\
(\mathrm{V} / \mathrm{sec})\end{array}$ & $\begin{array}{c}\text { Rate of Voltage } \\
\text { Decrease in Detailed } \\
\text { Secondary } \\
(\mathrm{V} / \mathrm{sec})\end{array}$ & $\begin{array}{c}\text { Percentage } \\
\text { Voltage } \\
\text { Error }\end{array}$ \\
\hline 2 & 0 & -0.00039 & -0.0004 & 98.41 \\
\hline 4 & 40.75 & -0.02067 & -0.1158 & 22.85 \\
\hline 6 & 47.71 & 0.03379 & -0.1650 & 147.00 \\
\hline 8 & 0 & 0.00033 & -0.0003 & 101.23 \\
\hline 10 & 0 & 0.00391 & -0.0034 & 104.02 \\
\hline 12 & 40.90 & 0.03196 & -0.2475 & 107.80 \\
\hline 14 & 25.23 & 0.02253 & -0.2139 & 110.18 \\
\hline 16 & 28.54 & 0.02765 & -0.2965 & 106.19 \\
\hline 18 & 19.85 & 0.01841 & -0.1115 & 106.13 \\
\hline 20 & 0 & 0.00817 & -0.0051 & 103.19 \\
\hline 24 & 40.75 & 0.01782 & -0.1835 & 104.86 \\
\hline
\end{tabular}

The absolute value of errors associated with the minimum voltage decrease rates versus number of customers on the secondary are illustrated in Figure 3.9. 


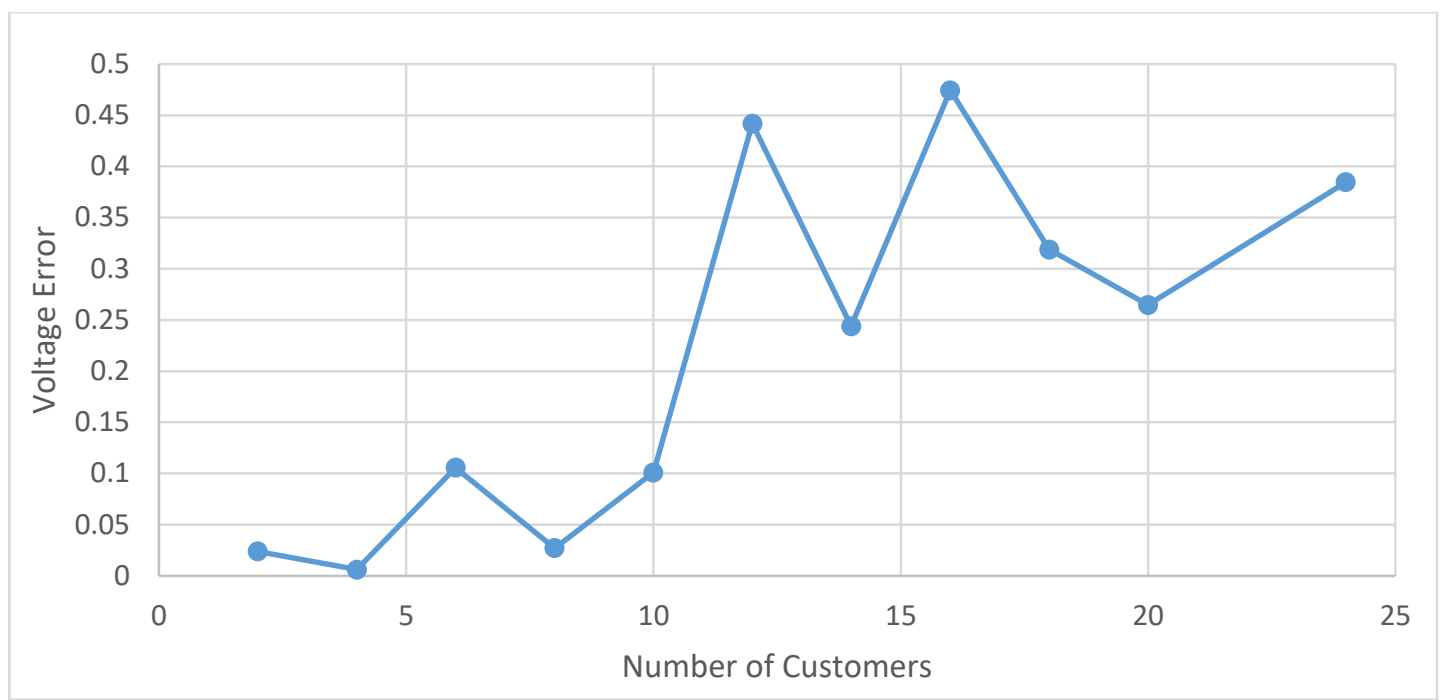

Figure 3.9: Absolute value of the errors associated with minimum voltage decrease rate between the simple and detailed models versus number of secondary customers The variations of percentage errors for the minimum voltage decrease rates, along with associated PV penetration values, versus number of customers on the secondary, are illustrated in Figure 3.10.

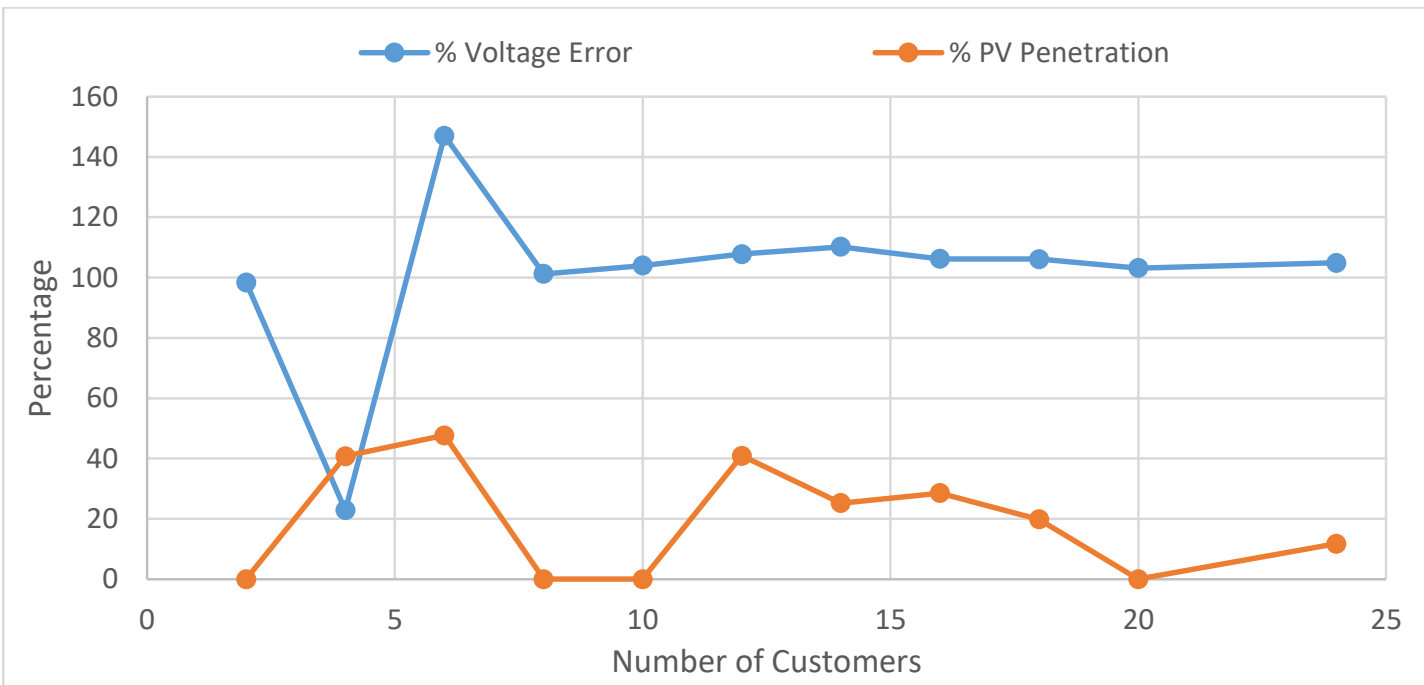

Figure 3.10: Percentage errors in prediction of minimum voltage decrease rates, along with associated PV penetration levels, versus number of secondary customers

The absolute value of errors associated with the maximum, minimum, and mean voltage decrease rates versus number of customers on the secondary are illustrated in Figure 3.11. Note that the minimum errors considered occur at the locations in the detailed secondary model where the voltage changes were a minimum. 


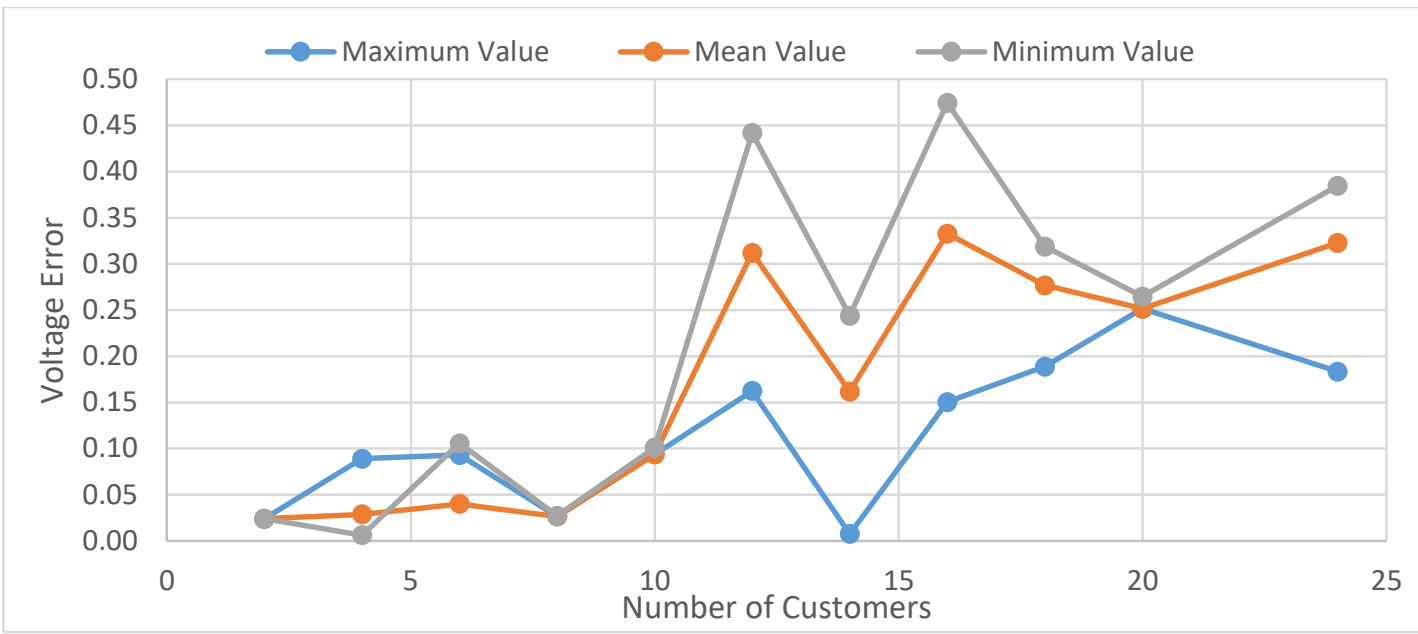

Figure 3.11: Absolute value of the errors associated with maximum, mean, and minimum voltage decrease rates between the simple and detailed models versus number of secondary customers

The variations of percentage errors for the maximum, minimum, and mean voltage decrease rates, along with associated PV penetration values, versus number of customers on the secondary, are illustrated in Figure 3.12.

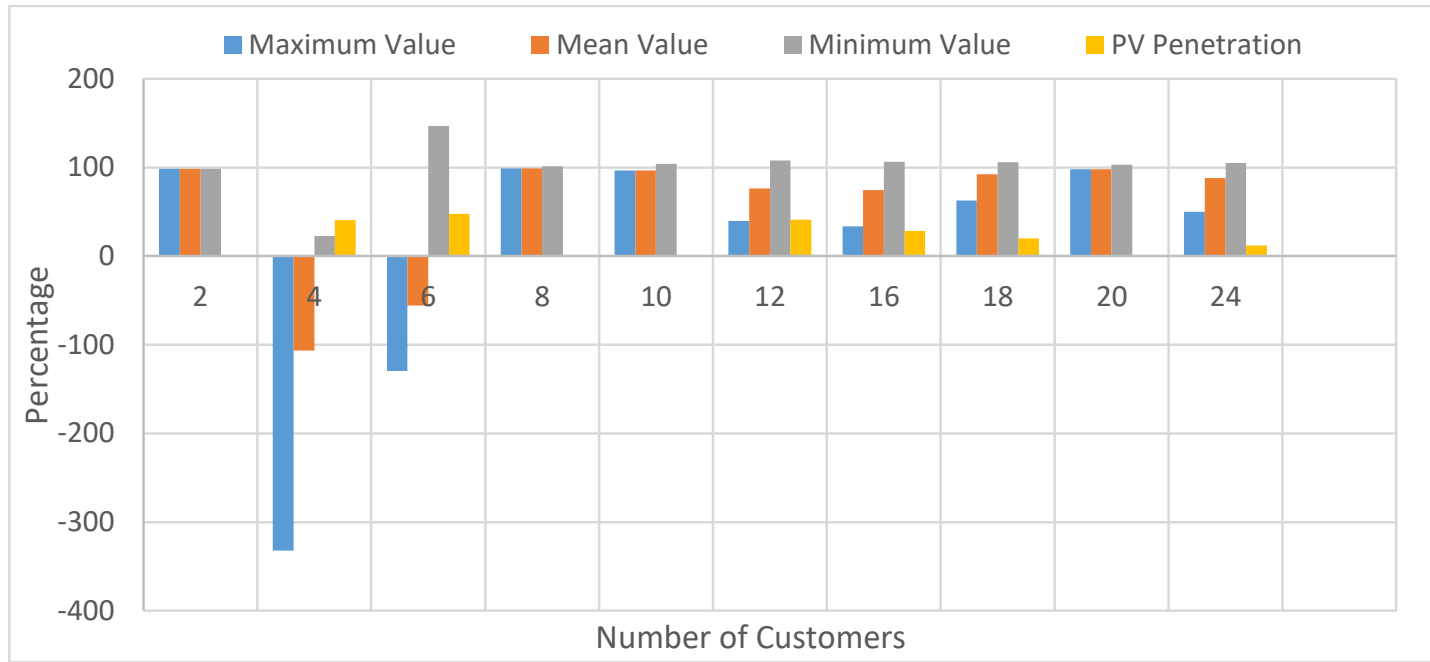

Figure 3.12: Percentage errors in prediction of maximum, mean, and minimum voltage decrease rates, along with associated PV penetration levels, versus number of secondary customers

\subsubsection{Scenario 2- Minimum Load}

In this scenario the minimum load, $1144 \mathrm{~kW}$, on the feeder is considered. Again we consider CMS results for locations with the maximum voltage decrease rate for the detailed secondary feeder model, the results of which are illustrated in Table 3.7. 
Table 3.7: Percentage voltage decrease errors for simple models and detailed secondary models

\begin{tabular}{|c|c|c|c|c|}
\hline $\begin{array}{c}\text { Number } \\
\text { of Loads }\end{array}$ & $\begin{array}{c}\text { Percentage } \\
\text { PV }\end{array}$ & $\begin{array}{c}\text { Rate of Voltage } \\
\text { Decrease in Simple } \\
\text { Secondary } \\
(\mathrm{V} / \mathrm{sec})\end{array}$ & $\begin{array}{c}\text { Rate of Voltage } \\
\text { Decrease in Detailed } \\
\text { Secondary } \\
(\mathrm{V} / \mathrm{sec})\end{array}$ & $\begin{array}{c}\text { Percentage } \\
\text { Voltage } \\
\text { Error }\end{array}$ \\
\hline 2 & 0 & -0.017853 & -0.000343 & 98.08 \\
\hline 4 & 115.80 & -0.025749 & -0.112038 & -335.11 \\
\hline 6 & 114.74 & -0.067377 & -0.154624 & -129.49 \\
\hline 8 & 0 & -0.020199 & -0.000329 & 98.37 \\
\hline 10 & 0 & -0.077548 & -0.002832 & 96.35 \\
\hline 12 & 128.77 & -0.301795 & -0.232630 & 22.92 \\
\hline 14 & 71.93 & -0.158129 & -0.204635 & -29.41 \\
\hline 16 & 105.74 & -0.325384 & -0.271211 & 16.65 \\
\hline 18 & 49.19 & -0.219541 & -0.107560 & 51.01 \\
\hline 20 & 0 & -0.203776 & -0.004621 & 97.73 \\
\hline 24 & 40.74 & -0.271053 & -0.169244 & 37.56 \\
\hline
\end{tabular}

The absolute value of errors associated with the maximum voltage decrease rates versus number of customers on the secondary are illustrated in Figure 3.13.

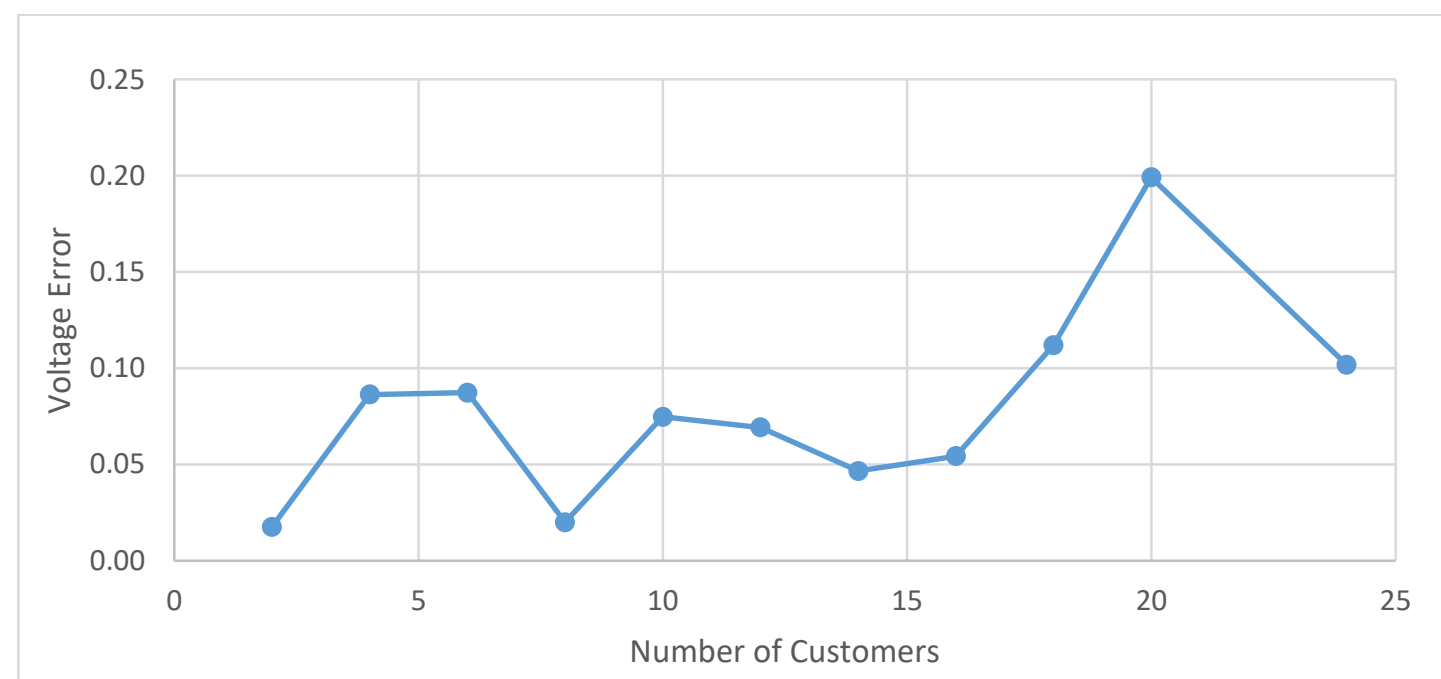

Figure 3.13: Absolute value of the errors associated with maximum voltage decrease rate between the simple and detailed models versus number of secondary customers

The variations of percentage errors for the maximum voltage decrease rates, along with associated PV penetration values, versus number of customers on the secondary, are illustrated in Figure 3.14. 


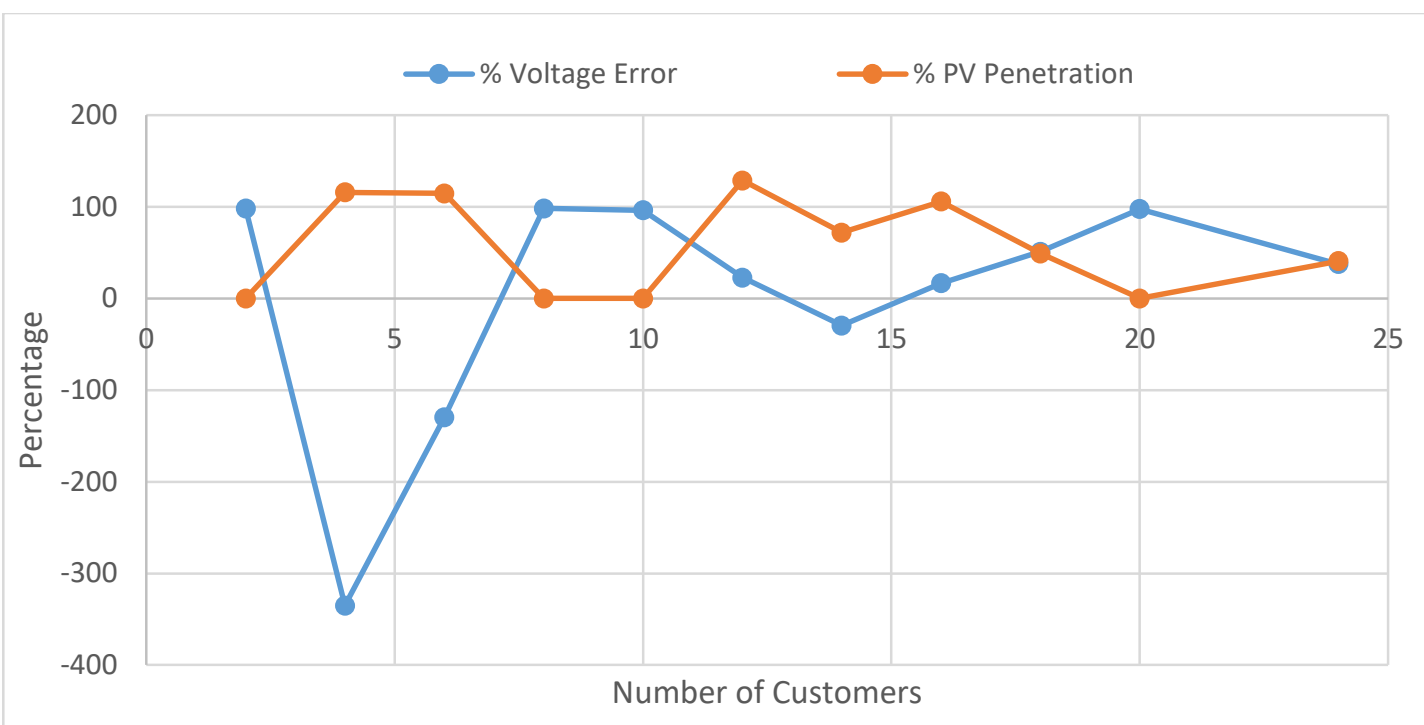

Figure 3.14: Percentage errors in prediction of maximum voltage decrease rates, along with associated PV penetration levels, versus number of secondary customers

The CMS results for locations with the mean voltage decrease rates are shown in Table 3.8.

Table 3.8: Percentage voltage decrease errors for simple models and detailed secondary models

\begin{tabular}{|c|c|c|c|c|}
\hline $\begin{array}{c}\text { Number } \\
\text { of Loads }\end{array}$ & $\begin{array}{c}\text { Percentage } \\
\text { PV }\end{array}$ & $\begin{array}{c}\text { Rate of Voltage } \\
\text { Decrease in Simple } \\
\text { Pecondary } \\
(\mathrm{V} / \mathrm{sec})\end{array}$ & $\begin{array}{c}\text { Rate of Voltage } \\
\text { Decrease in Detailed } \\
\text { Secondary } \\
(\mathrm{V} / \mathrm{sec})\end{array}$ & $\begin{array}{c}\text { Percentage } \\
\text { Voltage } \\
\text { Error }\end{array}$ \\
\hline 2 & 0.00 & -0.017853 & -0.000343 & 98.08 \\
\hline 4 & 115.80 & -0.025749 & -0.053233 & -106.74 \\
\hline 6 & 114.74 & -0.067377 & -0.103908 & -54.22 \\
\hline 8 & 0.00 & -0.020199 & -0.000320 & 98.42 \\
\hline 10 & 0.00 & -0.077548 & -0.002824 & 96.36 \\
\hline 12 & 128.77 & -0.301795 & -0.090324 & 70.07 \\
\hline 14 & 71.93 & -0.158129 & -0.055584 & 64.85 \\
\hline 16 & 105.74 & -0.325384 & -0.102029 & 68.64 \\
\hline 18 & 49.19 & -0.219541 & -0.021490 & 90.21 \\
\hline 20 & 0.00 & -0.203776 & -0.004620 & 97.73 \\
\hline 24 & 40.74 & -0.271053 & -0.038378 & 85.84 \\
\hline
\end{tabular}

The absolute value of errors associated with the mean voltage decrease rates versus number of customers on the secondary are illustrated in Figure 3.15. 


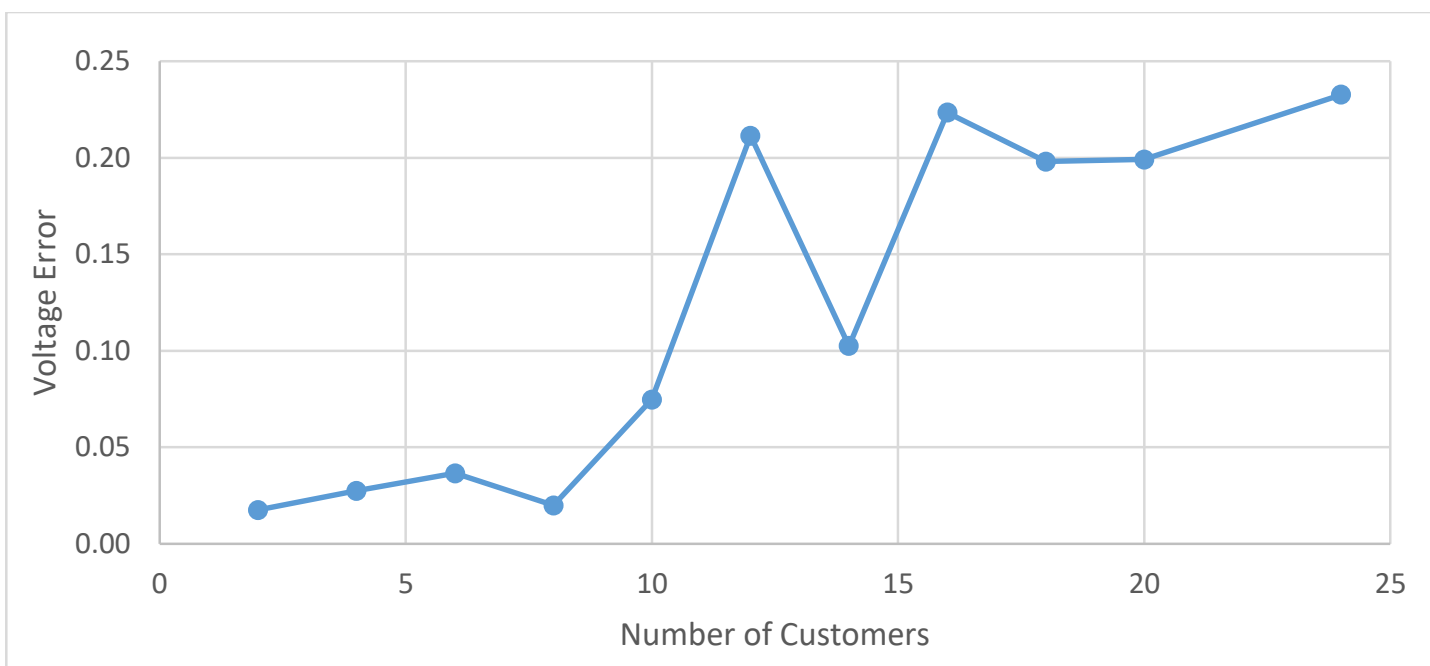

Figure 3.15: Absolute value of the errors associated with mean voltage decrease rate between the simple and detailed models versus number of secondary customers

The variations of percentage errors for the mean voltage decrease rates, along with associated PV penetration values, versus number of customers on the secondary, are illustrated in Figure 3.16.

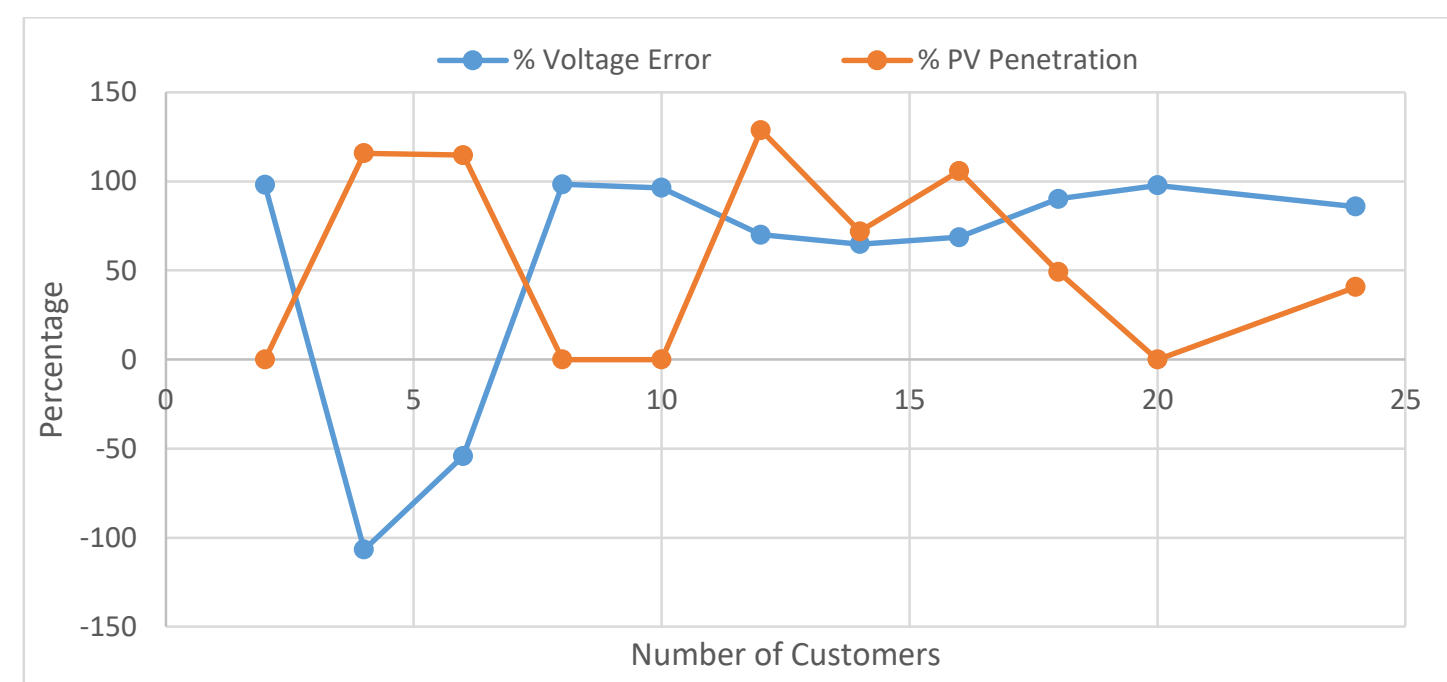

Figure 3.16: Percentage errors in prediction of mean voltage decrease rates, along with associated PV penetration levels, versus number of secondary customers

The CMS results for locations with the minimum voltage decrease rates are shown in Table 3.9. 
Table 3.9: Percentage voltage decrease errors for simple models and detailed secondary models

\begin{tabular}{|c|c|c|c|c|}
\hline $\begin{array}{c}\text { Number } \\
\text { of Loads }\end{array}$ & $\begin{array}{c}\text { Percentage } \\
\text { PV }\end{array}$ & $\begin{array}{c}\text { Rate of Voltage } \\
\text { Decrease in Simple } \\
\text { Pecondary } \\
(\mathrm{V} / \mathrm{sec})\end{array}$ & $\begin{array}{c}\text { Rate of Voltage } \\
\text { Decrease in Detailed } \\
\text { Secondary } \\
(\mathrm{V} / \mathrm{sec})\end{array}$ & $\begin{array}{c}\text { Percentage } \\
\text { Voltage } \\
\text { Error }\end{array}$ \\
\hline 2 & 0.00 & -0.01785 & -0.00034 & 98.08 \\
\hline 4 & 115.80 & -0.02575 & -0.01937 & 24.78 \\
\hline 6 & 114.74 & -0.06738 & -0.02761 & 59.02 \\
\hline 8 & 0.00 & -0.02020 & -0.00031 & 98.44 \\
\hline 10 & 0.00 & -0.07755 & -0.00282 & 96.37 \\
\hline 12 & 128.77 & -0.30180 & -0.02711 & 91.02 \\
\hline 14 & 71.93 & -0.15813 & -0.01817 & 88.51 \\
\hline 16 & 105.74 & -0.32538 & -0.02209 & 93.21 \\
\hline 18 & 49.19 & -0.21954 & -0.01594 & 92.74 \\
\hline 20 & 0.00 & -0.20378 & -0.00461 & 97.74 \\
\hline 24 & 40.74 & -0.27105 & -0.01672 & 93.83 \\
\hline
\end{tabular}

The absolute value of errors associated with the minimum voltage decrease rates versus number of customers on the secondary are illustrated in Figure 3.17.

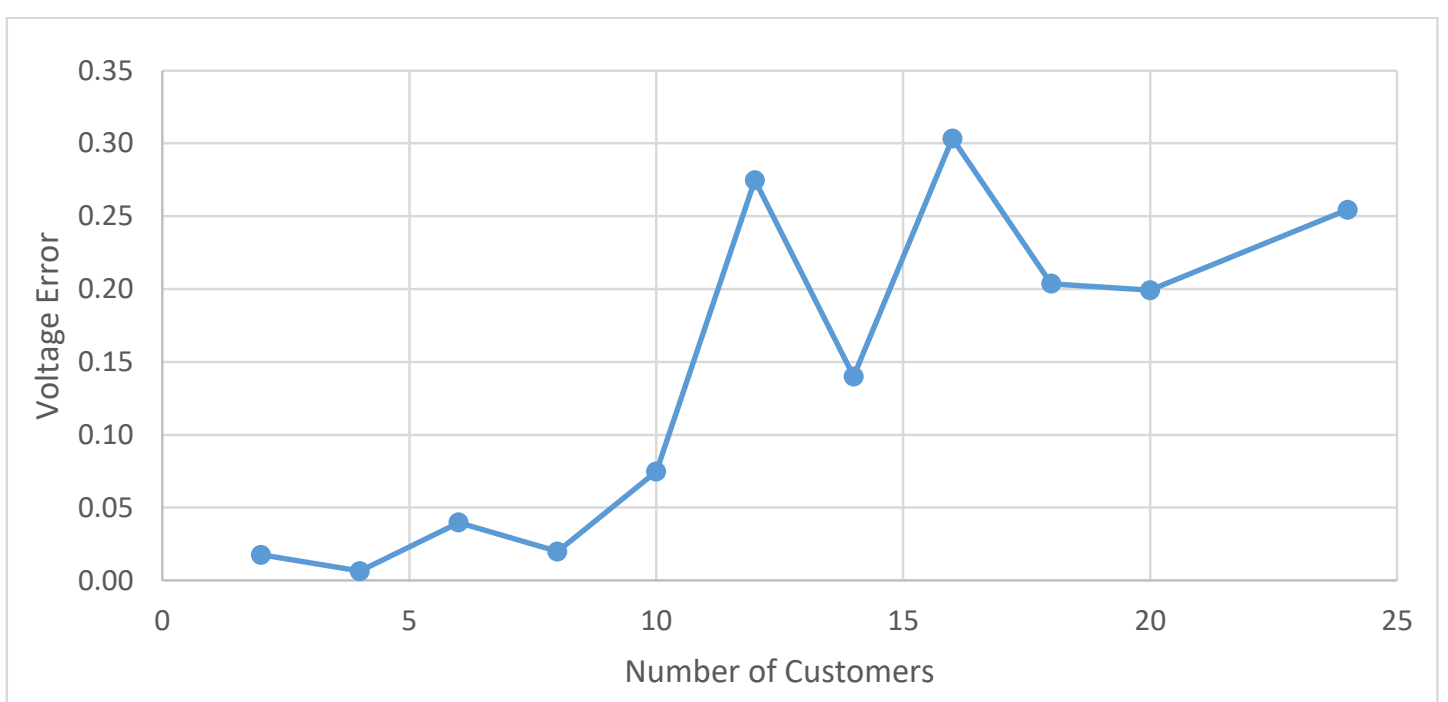

Figure 3.17: Absolute value of the errors associated with minimum voltage decrease rate between the simple and detailed models versus number of secondary customers

The variations of percentage errors for the minimum voltage decrease rates, along with associated PV penetration values, versus number of customers on the secondary, are illustrated in Figure 3.18. 


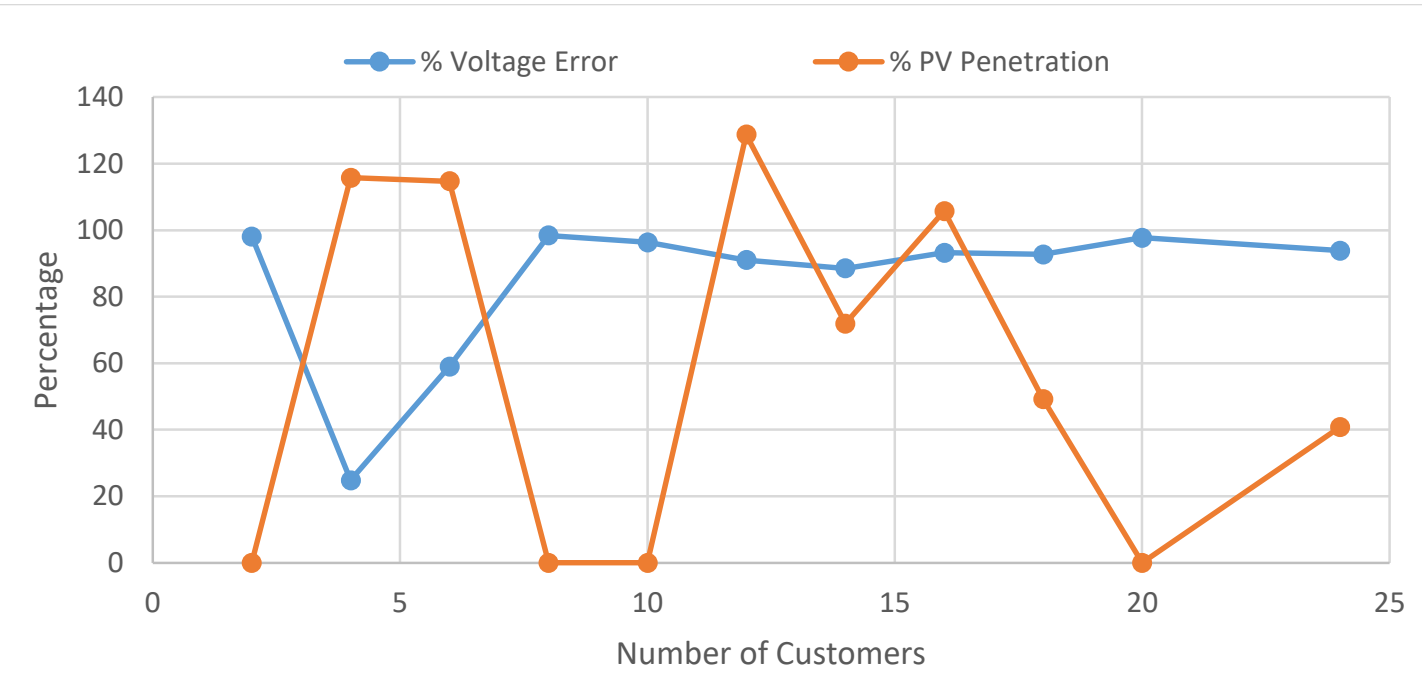

Figure 3.18: Percentage errors in prediction of minimum voltage decrease rates, along with associated PV penetration levels, versus number of secondary customers

The absolute value of errors associated with the maximum, minimum, and mean voltage decrease rates versus number of customers on the secondary are illustrated in Figure 3.19. Note that the minimum errors considered occur at the locations in the detailed secondary model where the voltage changes were a minimum.

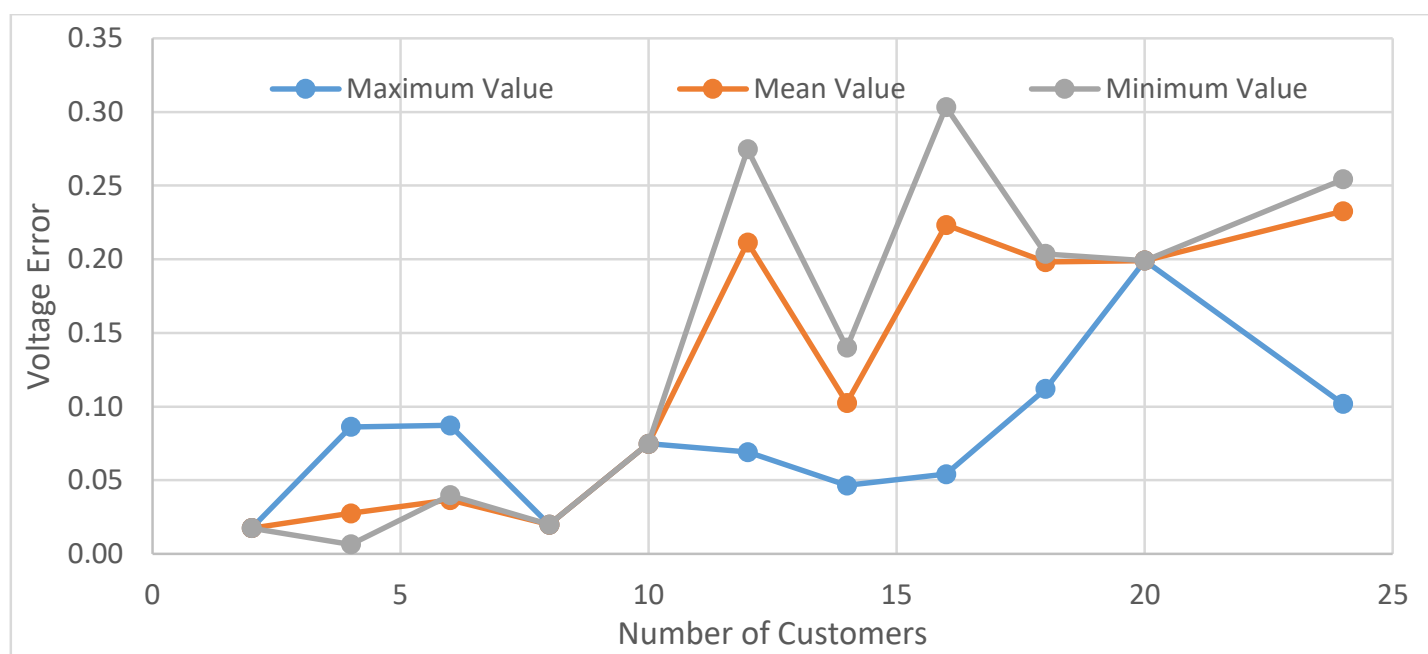

Figure 3.19: Absolute value of the errors associated with maximum, mean, and minimum voltage decrease rates between the simple and detailed models versus number of secondary customers

The variations of percentage errors for the maximum, minimum, and mean voltage decrease rates, along with associated PV penetration values, versus number of customers on the secondary, are illustrated in Figure 3.20. 


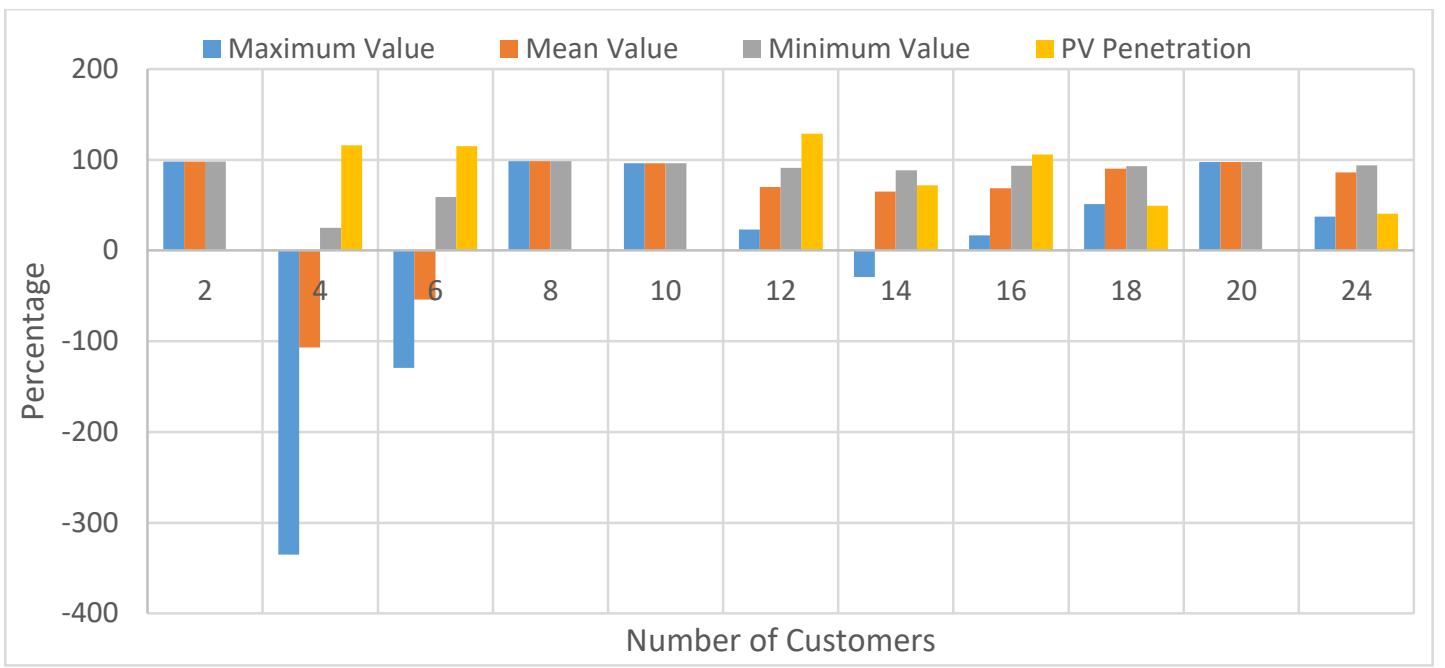

Figure 3.20: Percentage errors in prediction of maximum, mean, and minimum voltage decrease rates, along with associated PV penetration levels, versus number of secondary customers

3.3 Inferences from the results obtained; Discussions on reasons justifying the difference in results obtained from the two analysis/modelling approaches

Traditionally aggregated load and generation models have been employed when simulating the secondary side of distribution transformers. With detailed secondary models each load and solar PV generator on the secondary is modeled individually, where exact geographical locations can be taken into account by a cloud motion simulator. Analysis results between a feeder model using simple secondary circuit models (i.e., aggregated load and generation) and the same feeder model except using detailed secondary circuit models, have been compared. Some of the observations based on the simulations results are:

- From Figure 3.1 it is observed that the locations with the highest voltage decrease rates vary significantly between the simple and detailed models. Also, the magnitude of voltage decrease rates differs in simple secondary and detailed secondary models. The primary reason for the error is due to fact that in simple secondary models spatial diversity of PV is ignored. The spatial diversity of PV modules can reduce the overall variability. When PV generators are modeled with geographical diversity, some PV 
modules may be covered by the clouds while the rest experience clear skies. Also, the arrangement of PV modules, cloud speed, and the timescale impacts the amount of variability due to spatial diversity.

- Results from Figure 3.11 and Figure 3.12 resemble the results from Figure 3.19 and Figure 3.20 respectively. In both scenarios, results indicate that the voltage decrease rate errors between detailed and simple secondary circuits are in the range of $-340 \%$ to $100 \%$ and in simple secondary models there is voltage overestimation for most of the cases. Clearly, load and PV distribution/penetration and the impedance of the detailed secondary conductors affect the error value.

- It was observed that in the secondary circuits with zero percent PV penetration, the error between the two models could be as high as $100 \%$. This indicates that the error at any location with PV in a simple secondary circuit will also be reflected at locations with no PV penetration. The error value will depend on circuit parameters, like load and PV distribution/penetration and the impedance of the detailed secondary conductors.

- Voltage flicker calculations are higher with simple secondary models than their corresponding detailed secondary models, as seen in Table 3.3 and Figure 3.3. As maximum PV penetration on the feeder is limited due to voltage flicker concern, the use of simple models could unnecessarily limit the maximum PV penetration on a feeder. Most distribution feeders can accommodate more PV penetration if accurate, detailed modeling is used in the analysis.

- The rise or fall in voltages lead to increases in operation of voltage regulators and switched capacitor banks. Due to high voltage drop or rise estimation from analysis performed using the simple secondary circuits, the maintenance frequency 
requirement and equipment life cycle would be pessimistically estimated. However, with the detailed secondary circuits, the more accurate value of voltage rise or drop will better estimate maintenance requirements and life cycle of control devices.

- Results from section 3.2.1 and section 3.2.2 show that even at secondary locations with no PV penetration, there are drops in voltage levels. Changes in PV output at any location in the circuit also impact other locations. 


\section{Chapter 4: Conclusions and Future Work}

\subsection{Summary of results}

A new approach for modelling and analyzing distribution systems with solar generation is investigated in this thesis. The idea is to simulate cloud shadows which move over a distribution feeder with embedded PV generation. In this investigation detailed secondary network models were used and the locational diversity of the distributed generation was maintained. With detailed secondary models, the accuracy of modeling the distributed PV generation is improved and studies based on PV modeling become more realistic. This analysis approach provides more accurate estimates of the maximum penetration of renewables into the network than traditional approaches. This analysis approach also provides greater accuracy as to investigating mitigation measures, such as improved voltage control.

The analysis in this thesis used a cloud motion simulator. With the availability of three meteorological inputs, i.e., cloud cover, cloud velocity and cloud movement direction, the impact of clouds on the system can be predicted. We can receive these inputs from the Automated Surface Observing Systems (ASOS) of the National Weather Service (NWS).

The case study in chapter 3 compared analysis results between simple secondary models and detailed secondary models. A summary of the contributions of the thesis based on the results obtained are:

1. The main contribution of the thesis is to highlight the importance of detailed secondary models in identifying the locations with the highest impact under changing weather conditions, while considering spatial diversity neglected in previous studies. 
2. With detailed secondary models, each load and solar PV generator is modeled individually, with exact geographical locations taken into account as clouds pass over the circuit. Comparing calculations resulting from using the detailed secondary models with the traditional simple secondary models, it was shown that voltage changes calculated using simple secondary models are overly conservative.

3. A general trend in voltage errors between calculations based on simple secondary models and their corresponding detail secondary models has been demonstrated, where the voltage errors increase with the increase in the number of customers being served on the secondary.

4. Voltage flicker limits the maximum PV generation on a given feeder. It has been shown that flicker value calculations are higher for simple secondary models than their corresponding detailed secondary models.

\subsection{Future work}

Most distribution generation research has primarily focused on the integration of renewables, such as PV. This trend has started to change with the introduction of energy storage, which provides a range of applications from customer peak charge reduction to resiliency. There is growing interest for the integration of energy storage at the distribution level. Elon Musk of Tesla Motors has announced the Power Wall (a lithium-ion battery) for residential homes [19]. Energy storage, combined with PV systems, will help resolve issues associated with PV variability. In the future energy storage, both on primary and secondary distribution, needs to be considered. It is anticipated that inverter based battery storage will help better control voltage fluctuations and thereby increase PV hosting capacity. 


\section{References}

[1] R. Seguin, J. Woyak, D. Costyk, J. Hambrick and B. Mather, "High-Penetration PV Integration Handbook for Distribution Engineers," in National Renewable Energy Laboratory, Golden, CO NREL/TP-5D00-63114, 2016.

[2] B. Owens, "The Rise of Distributed Power," in General Electric, 2014.

[3] "Solar Distributed Generation," in American Public Power Association, February, 2016.

[4] GTM Research/SEIA: U.S. Solar Market Insight, June 2017. [Online]. Available: http://www.seia.org/research-resources/solar-market-insight-report-2017-q2.

[5] Y. Agalgaonkar, B. Pal and R. Jabr, "Distribution Voltage Control Considering the Impact of PV Generation on Tap Changers and Autonomous Regulators," in IEEE Transactions on Power Systems, January, 2017.

[6] W. H. Kersting, Distribution System Modeling and Analysis, Third Edition, CRC Press, 2012.

[7] T. Y. Tiam and D. S. Kirschen, "Impact on the power system of a large penetration of photovoltaic generation," in IEEE Power Eng. Soc. Gen. Meet, 2007, pp. 1-8.

[8] R. Tonkoski and L. C. Lopes, "Voltage regulation in radial distribution feeders with high penetration of photovoltaic," in IEEE Energy 2030 Conf., 2008, pp. 1-7.

[9] M. K. Singh and P. N. Reddy, "A fast Adaptive Protection Scheme for Distributed Generation Connected Networks with Necessary Relay Coordination," in Students Conference on Engineering and Systems (SCES), April 2013, pp. 1-5. 
[10] E. Demirok, D. Sera, R. Teodorescu, P. Rodriguez and U. Borup, "Clustered PV inverters in LV networks: An overview of impacts and comparison of voltage control strategies," in IEEE Electrical Power Energy Confer5, 2009, pp. 1-6.

[11] A. Parchure, S. J. Tyler, M. A. Peskin, K. Rahimi and R. P. Broadwater, "Investigating PV Generation Induced Voltage Volatility for Customers Sharing a Distribution Service Transformer," in IEEE Transactions on Industry Applications, vol. 53, no. 1, pp. 71-79, Jan.-Feb. 2017.

[12] G. W. Chang, Y. H. Chen, L. Y. Hsu, Y. Y. Chen, Y. R. Chang and Y. D. Lee, "Study of Impact on High PV-penetrated Feeder Voltage Due to Moving Cloud Shadows," in International Symposium on Computer, Consumer and Control, 2016.

[13] K. Rahimi, S. Mohajeryami and A. Majzoobi, "Effects of photovoltaic systems on power quality," in North American Power Symposium, Denver, CO, 2016, pp. 1-6.

[14] M. Suri, T. Cebecauer, T. Skoczek, R. Marais, C. Mushwana, J. Reinecke and A. Meyer, "Cloud Cover Impact On Photovoltaic Power Production in South Africa," in 2nd South African Solar Energy Conference, Port Elizabeth, South Africa, 2014.

[15] R. Yan and T. K. Saha, "Investigation of Voltage stability for residential customers due to high photovoltaic penetrations," in IEEE Trans. Power Syst., vol. 27, no. 2, pp. 651-662, May 2012.

[16] P. D. Ferreira, P. M. Carvalho, L. A. Ferreira and M. D. Ilic, "Distributed energy resources integration challenges in low-voltage networks: Voltage control limitations and risk of cascading," in IEEE Trans. Sustainable Energy, vol. 4, no. 4, pp. 82-88, Jan. 2013. 
[17] A. Agrawal, K. Rahimi, R. P. Broadwater and J. Bank, "Performance of PV generation feedback controllers: Power factor versus Volt-VAR control strategies," in North American Power Symposium, Charlotte, NC, 2015.

[18] K. Rahimi, S. Omran, M. Dilek and R. Broadwater, "Quasi-steady-state Computation of Voltage Flicker with Cloud Motion Simulator," in IEEE Power and Energy Conference, Urbana, IL, 2017, pp. 1-6.

[19] "Fortune: Top five takeaways from Elon Musk's Tesla Energy reveal," May 2015. [Online]. Available: http://fortune.com/2015/05/01/tesla-energy-reveal/.

[20] B. Palmintier, R. Broderick, B. Mather, M. Coddington, K. Baker, F. Ding, M. Reno, M. Lave and A. Bharatkumar, "On the path to sunshot: Emerging issues and challenges in integrating solar with the distribution system," in Tech. Rept. NREL/TP-5D00-65331, National Renewable Energy Laboratory, May 2016.

[21] "About 30\% of distributed solar capacity is owned by third parties," EIA, December 2016. [Online]. Available: https://www.eia.gov/todayinenergy/detail.php?id=29052. 